This item was submitted to Loughborough's Research Repository by the author.

Items in Figshare are protected by copyright, with all rights reserved, unless otherwise indicated.

\title{
A taxonomic classification of visual design representations used by industrial designers and engineering designers
}

PLEASE CITE THE PUBLISHED VERSION

http://dx.doi.org/10.2752/175630610X12877385838803

PUBLISHER

(C) Berg

VERSION

AM (Accepted Manuscript)

LICENCE

CC BY-NC-ND 4.0

\section{REPOSITORY RECORD}

Pei, Eujin, R.I. Campbell, and Mark A. Evans. 2019. "A Taxonomic Classification of Visual Design Representations Used by Industrial Designers and Engineering Designers". figshare.

https://hdl.handle.net/2134/10889. 
This item was submitted to Loughborough's Institutional Repository (https://dspace.lboro.ac.uk/) by the author and is made available under the following Creative Commons Licence conditions.

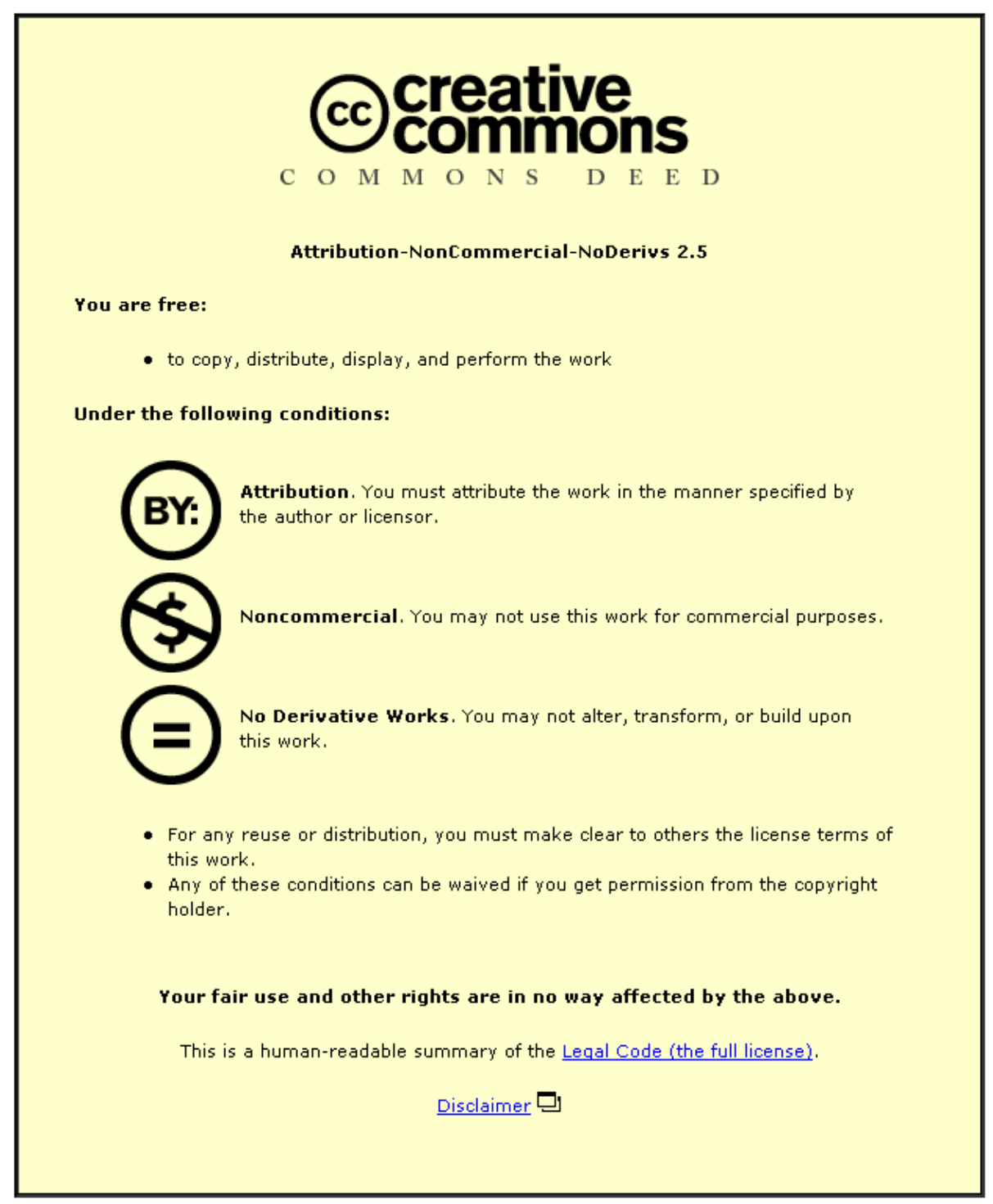

For the full text of this licence, please go to: http://creativecommons.org/licenses/by-nc-nd/2.5/ 


\title{
A TAXONOMIC CLASSIFICATION OF VISUAL DESIGN REPRESENTATIONS USED BY INDUSTRIAL DESIGNERS AND ENGINEERING DESIGNERS
}

\begin{abstract}
In the context of New Product Development (NPD), research has shown that not having a common understanding of Visual Design Representations (VDRs) has affected collaboration between industrial designers and engineering designers when working together. The aim of the research presented in this paper was two-fold. Firstly, to identify the representations employed by industrial designers and engineering designers during NPD from a literature survey. Secondly, to define and categorise these representations in the form of a taxonomy that is a systematic organisation of VDRs that are presently dispersed in the literature. For the development of the taxonomy, four measures encompassing orthogonality, spanning, completeness and usability were employed. It resulted in four groups consisting of sketches, drawings, models and prototypes. Validation was undertaken by means of an interview survey and further presenting the taxonomy at an international conference. The results showed that there were no issues raised by the respondents concerning the structure of the taxonomy or its components.
\end{abstract}

\section{KEYWORDS}

visual design representations, industrial design, engineering design 


\section{BACKGROUND}

Today's highly competitive global markets have highlighted the importance of industrial design and engineering design collaboration in New Product Development (NPD). To avoid costly rework and to reduce development time, effective externalisation of design concepts amongst team members is crucial (Alisantoso et al. 2006). The ideas that initially take place in the form of Visual Design Representations (VDRs) must be well externalised and understood if they are to be shared with others (Goldschmidt 1997, Pipes 2007, Eissen and Steur 2008).

VDRs reproduce properties of a design proposal through physical or virtual means in the form of $2 \mathrm{D}$ or $3 \mathrm{D}$ media. They are employed to visualise, communicate and store information (Tang 1991, Persson 2002, Do 2005); to externalise thoughts (Larkin and Simon 1987, Goldschmidt and Porter 2004); as a thinking and reflective tool (Ferguson 1992, Suwa et al. 1998, Saddler 2001, Visser 2006); to verify decisions (Olofsson and Sjölén 2005); to derive new ideas (Scrivener et al. 2000, Eckert and Boujut 2003); as an extension to short term memory (Lipson and Shpitalni 2000); to record ideas (Baskinger 2008); and as a persuasive aid (Menezes and Lawson 2006). More importantly, these representations allow team members to see a design problem at the same level so as to create a shared mental image of the product (Goldschmidt 2007).

Despite these advantages, the ambiguous nature and the absence of a common understanding of representations has led to miscommunication, misinterpretation and ineffective working processes (Goel 1995). In addition, 
disharmony may occur when team members employ or view these representations differently. For instance, engineering designers produce technical details for manufacture based on quality, performance and cost (Flurscheim 1983), while industrial designers deliver sketches and physical models based on aesthetic attributes. Another difference is that engineering designers associate models with engineering principles, functional mechanisms and production issues; whereas industrial designers employ representations mainly for appearance and usability (Fiske 1998, Veveris 1994). Communication also becomes difficult because each member has their own vocabulary suited to their discipline-specific activities. Other problems arise when members come from different workplace cultures with different priorities, thinking styles and values (Erhorn and Stark 1994, Ostwald 1995). An individual may interpret the same data differently or make a different selection from the same data (Boujut and Laurillard 2002). Lastly, even though the language may be similar, identical words may have different meanings (Kalay 2001).

According to Kleinsmann and Dong (2007), communication becomes efficient only when members of a team have a shared understanding about the content. While some professions employ formal systems such as ISO standards and engineering terminology, the design profession has representations that are less established, ill-defined and imprecise (Saddler 2001). While ambiguity may be helpful for creativity, it could lead to inaccurate and inconsistent meanings. The ambiguous nature makes it difficult for engineering designers to comprehend and recognise how a representation would relate towards the technical parameters of a product. 
Therefore, it is suggested that communication and interaction among interdisciplinary members during NPD can be enhanced by having a common understanding in the use of representations. This has been proposed by Mathew (1997) who claimed that having a common understanding of these definitions would ensure that interpretations remain consistent among the stakeholders. Subsequently, Stacey and Eckert (2003) added that ambiguity and vagueness can be resolved by being more specific about the design intent. Lastly, Persson and Warell (2003) stated that a language which is well understood by both sender and receiver is the first step towards enhancing understanding among disciplines. In light of this, this research aims to provide a clearer and more consistent understanding of the VDRs employed by industrial designers and engineering designers during NPD.

\section{DEVELOPMENT OF THE VDR TAXONOMY}

The term 'taxonomy' is derived from the Greek words 'taxis' (arrangement), and 'nomia' (distribution). According to the Oxford Dictionary (2008), the term 'taxonomy' refers to a scheme of classification concerned with the arrangement of information, as well as the transmission, clarification and organisation of data (Jeffrey 1982, Derr 1973, Gershenson and Stauffer 1999, Ostergaard and Summers 2009). Despite various attempts by scholars to classify representations, they have been either incomplete or do not incorporate those from industrial design and engineering design domains (Engelbrektsson and Soderman 2004, Johansson et al. 2001, Tovey 1989, Ferguson 1992, Veveris 1994, Goldschmidt 1997, Cross 1999, Do et al. 2000, Ullman 2003). 
Similar to the 'Taxonomy on Drawing for Design' as proposed by Schenk (2007), the purpose of this taxonomy is to characterise, classify and provide a comparative analysis of various VDRs employed by industrial designers and engineering designers during NPD. While representations could be categorised by their shape and its use (Botturi and Stubbs 2008), the key purpose of developing this taxonomy is to ensure that the significant attributes of a VDR are accurately described and represented.

The next step concerns data collection, where information has been obtained by undertaking a thorough survey of relevant literature concerning industrial design and engineering design. Each VDR encountered was sorted into appropriate categories and this was repeated until no further items could be identified. From the survey, it was found that representations were presented in either a two-dimensional or three-dimensional medium. A two-dimensional representation encompassed either sketches or drawings, whereas threedimensional representations included models or prototypes. The four key groups of sketches, drawings, models and prototypes are shown in Table 1 and they are further divided into sub-groups which are discussed in later sections.

For this research, a sketch has been defined as a preliminary, rough representation without detail, usually rapidly executed to present only key elements of the design. They are sketched in free-hand and are often not to scale. In contrast, a drawing is a formal arrangement of lines that determine a particular form and are highly structured to formalise and verify aspects of the design. They are made in accordance with a set of rules and are drafted with 
mechanical instruments or CAD systems to scale. Models are used to reproduce the rough functional properties of a design. The tangible and threedimensional properties of a model allow developers to explain the function, performance and aesthetic aspects of a design. In contrast, prototypes are used to communicate and verify the final outlook and functionality of the product. Models are better suited during the early stages of development for problem solving and idea generation, whereas prototypes are employed towards the later stages to confirm and evaluate the aesthetics, ergonomics and performance of the product.

\begin{tabular}{|c|c|c|c|}
\hline \multicolumn{2}{|c|}{ Group } & Sub-group & Visual Design Representation \\
\hline \multirow{6}{*}{ 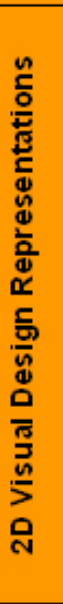 } & \multirow{4}{*}{ Sketches } & Personal Sketches & $\begin{array}{l}\text { Idea Sketch } \\
\text { Study Sketch } \\
\text { Referential Sketch } \\
\text { Mem ory Sketch }\end{array}$ \\
\hline & & Shared Sketches & $\begin{array}{l}\text { Coded Sketch } \\
\text { Information Sketch }\end{array}$ \\
\hline & & Persuasive Sketches & $\begin{array}{l}\text { Renderings } \\
\text { Inspiration Sketch }\end{array}$ \\
\hline & & Handover Sketches & Prescriptive Sketch \\
\hline & \multirow[b]{2}{*}{ Drawings } & Industrial Design Drawings & $\begin{array}{l}\text { Concept D rawings } \\
\text { Presentaion D rawing } \\
\text { Scenario \& Storyboard }\end{array}$ \\
\hline & & Engineering Design Drawings & $\begin{array}{l}\text { Diagram } \\
\text { Single-View Drawing } \\
\text { Multi-ViewDrawing } \\
\text { General Arrangement D rawing } \\
\text { Technical D rawing } \\
\text { Technical Illustration }\end{array}$ \\
\hline \multirow{4}{*}{ 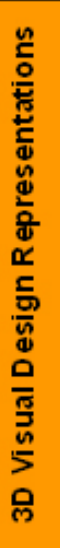 } & \multirow[b]{2}{*}{ Models } & Industrial Design Models & $\begin{array}{l}\text { 3D Sketch Model } \\
\text { Design Development Model } \\
\text { Appearance Model }\end{array}$ \\
\hline & & Engineering Design Models & $\begin{array}{l}\text { Fundional Concept Model } \\
\text { Concept of Operation Model } \\
\text { Production Concept Model } \\
\text { Assem bly Concept Model } \\
\text { Service Concept Model }\end{array}$ \\
\hline & \multirow[b]{2}{*}{ Prototypes } & Industrial Design Prototypes & $\begin{array}{l}\text { Appearance Protdype } \\
\text { Apha P rototype } \\
\text { Beta Prototype } \\
\text { Pre-Production P rototype }\end{array}$ \\
\hline & & Engineering Design Prototypes & $\begin{array}{l}\text { Experim ental P rototype } \\
\text { System Protdype } \\
\text { Final Hard ware Prototype } \\
\text { Tooling Prototype } \\
\text { Off-Tool Prototype }\end{array}$ \\
\hline
\end{tabular}

Table 1: Categories of Visual Design Representations 
The hierarchical classification in Figure 1 became the framework for the taxonomy. The group of sketches was further sub-categorised into personal, shared, persuasive and handover sketches; while drawings were subcategorised into industrial design and engineering design drawings. Models and prototypes were also sub-categorised as industrial design and engineering design models and prototypes.

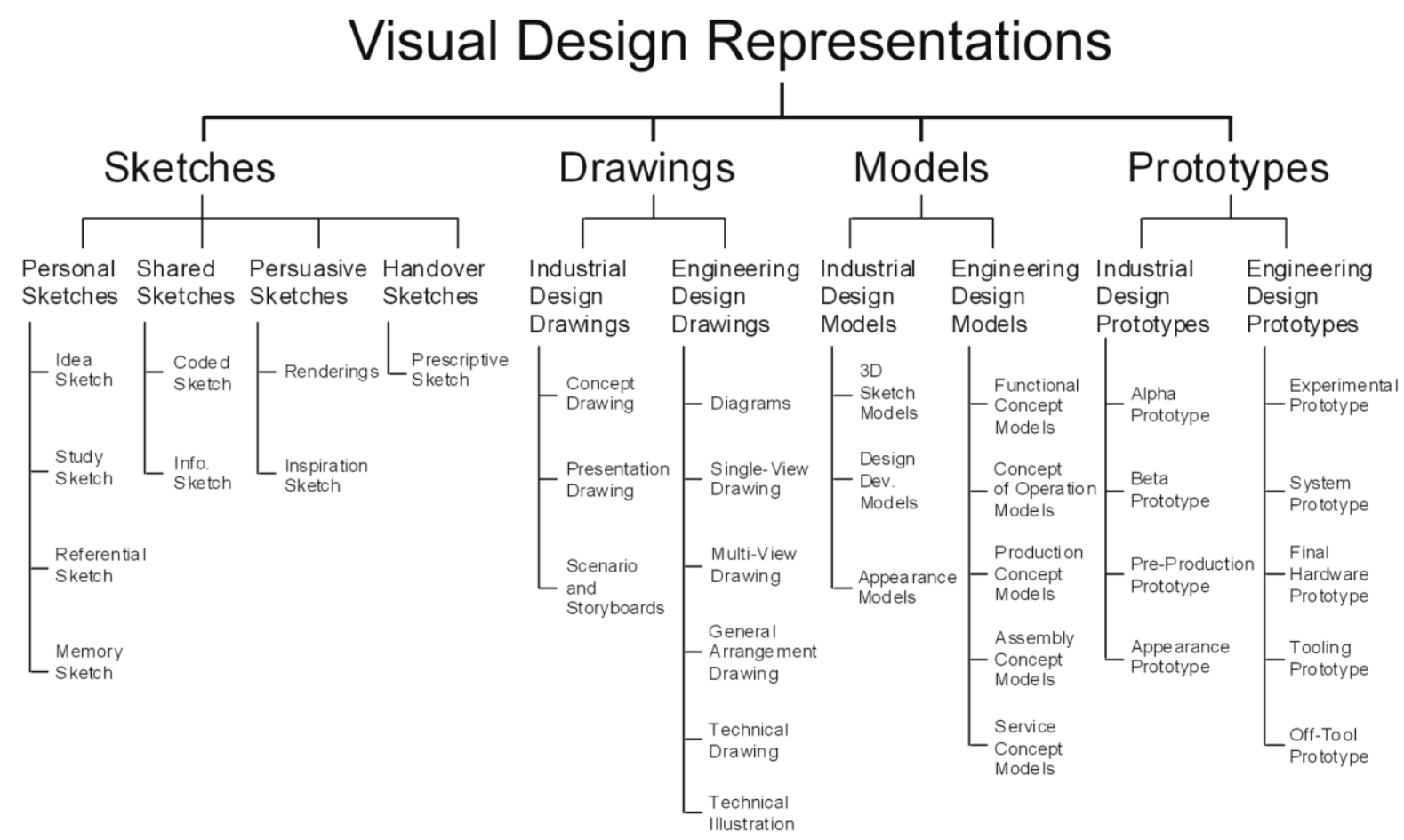

Figure 1: Taxonomy of Visual Design Representations

In structuring the taxonomy, four matrices encompassing orthogonality, spanning, precision and usability as employed by Ostergaard and Summers (2009) were adopted. These matrices were derived from the work of Derr (1973) and Gershenson and Stauffer (1999). Orthogonality seeks to ensure that there is no overlap of information within the taxonomy; while spanning refers to the breadth or coverage of the classification. Precision seeks to 
ensure that the taxonomy is sufficiently detailed; while usability is concerned with achieving ease of communication and understandability of the taxonomy.

\subsection{ORTHOGONALITY}

In terms of orthogonality, each of the four taxons have been clearly distinguished and to ensure that they were not repeated in other groups. Despite having a clear distinction among each taxon and its sub-groups, it is important to acknowledge that a representation may sometimes have more than one purpose due to its ambiguous nature. When that happens, the VDR may then fall into another category. For instance, it is not uncommon for engineering designers to build a single model that would be employed as a functional concept model and used as a concept of operation model. Similarly when an industrial designer further develops a rough 3D sketch model, it could then be classed as a design development model. Although this could make identifying a representation difficult, Houde and Hill (1997) suggested to first determine the purpose or function of the representation, as opposed to define what media or tools were used. For this study, distinguishing the taxons has been achieved by clarifying the purpose of each representation.

\subsection{SPANNING}

Spanning seeks to ensure that the breadth of the taxonomy is covered as much as possible. To achieve this, relevant literature concerning industrial design and engineering design was surveyed. With the exception of several papers and books, it was found that little work has been done to provide an inclusive source of reference for VDRs used by industrial designers and 
engineering designers during NPD. The Design Secrets series of books (IDSA 2003, Haller and Cullen 2006) provided several case studies but only briefly described some representations that were employed. Other publications focused solely on sketches or drawings (Tjalve et al. 1979, Olofsson and Sjölén 2005, Pavel 2005, Pipes 2007, Eissen and Steur 2008), while research by Author (2002) partially covered models and prototypes; and Cain (2005) only provided an overview of conventional and digital representations.

Taking information from these and other sources, VDRs that were found to be employed by industrial designers and engineering designers were sorted into appropriate categories and the literature was revisited to find additional evidence. During the survey, there were several representations that were identified but later omitted. For example, Tape drawings have been used by the automotive industry to create a representation of an automobile on large surfaces. However, this method of representation has been unpopular with mainstream industrial designers and therefore a decision was decided to omit this entry. While every effort has been undertaken to ensure the completeness of the taxonomy, the current selection may still be revised and re-evaluated over time.

\subsection{PRECISION}

The term precision is concerned with the detail of the taxonomy. This has been achieved by conducting a thorough survey of existing literature. In order to capture as much detailed information as possible, a second iteration (Figure 2) was developed to include images for each of these representations. According to Sorenson and Webb (1991), the use of visual examples as a 
form of reference would improve the level of detail for the user, allowing for greater clarity, as well as making it easier to recognise and identifying the representations.

\section{Visual Design Representations}

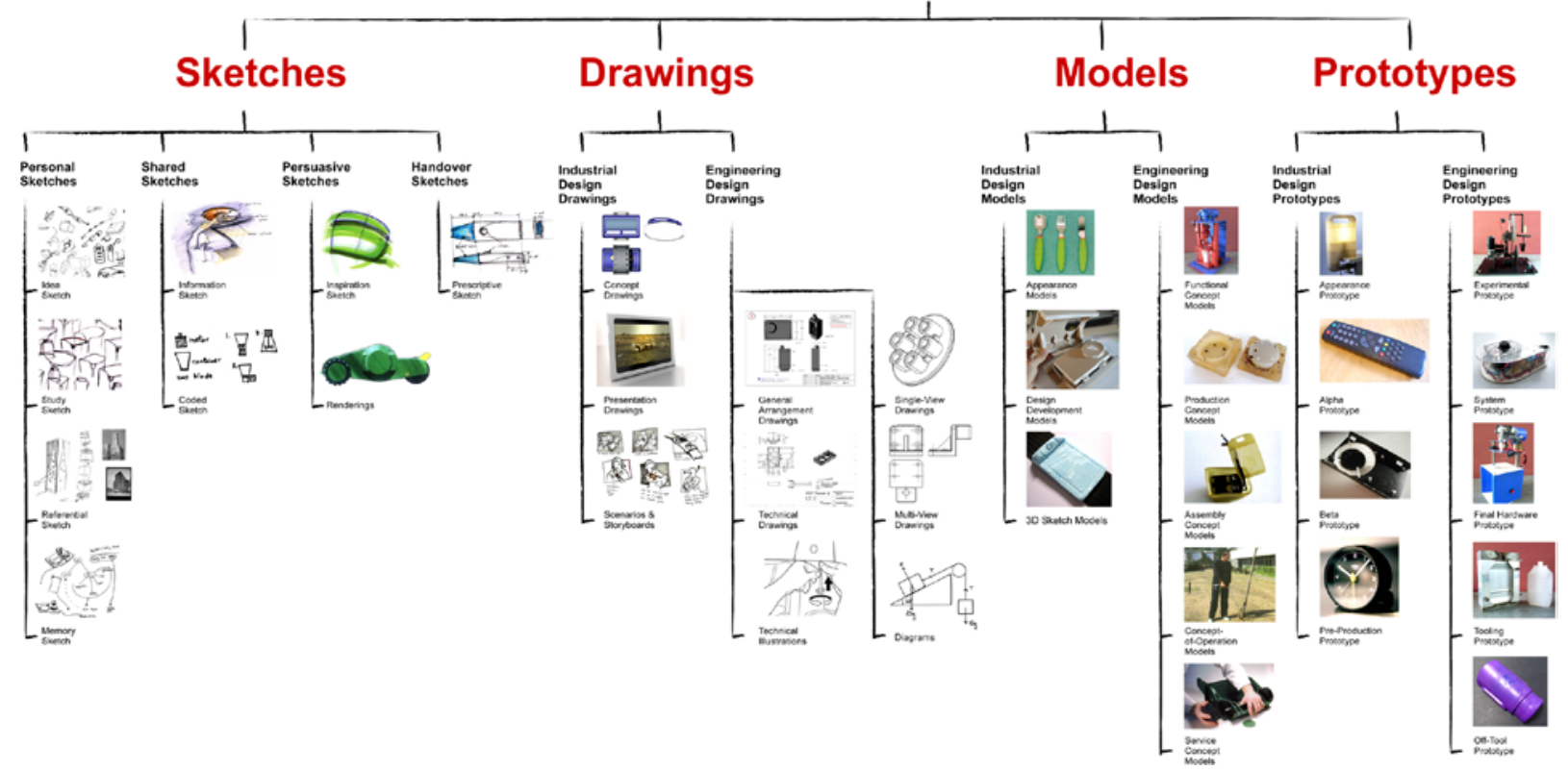

Figure 2: Revised taxonomy of Visual Design Representations

\subsection{USABILITY}

Usability seeks to ensure that the taxonomy is easy to communicate and understand. The hierarchical tree structure shown above (Figure 2) represents a systematic approach to organise and categorise the VDRs employed by industrial designers and engineering designers during NPD. The four taxons present a clear distinction in defining the representations and they are supplemented with images for clarity and understandability. This ensures that the taxonomy remains effective and is not cumbersome to understand. Having discussed the development of the taxonomy, the following sections shall now describe each of the taxons in detail. 


\section{SKETCHES}

A sketch is a preliminary, rough visual design representation of something without detail for the basis of a more finished product (Merriam-Webster Dictionary 1994, Dictionary of Art Terms 2003). More importantly, it is usually rapidly executed and presents only key elements of the design. Sketches comprise informal freehand marks without the use of instruments (Tjalve et al. 1979) and may for example, include draft lines, text, dimensions, and calculations that help explain the meaning, context and scale of the design (Ullman et al. 1990, McGown et al. 1998, Stacey and Eckert 2003). In addition, sketches are also accompanied with varying line weights to suggest depth, or over-tracing, redrawing and hatching to define a selection or to draw attention to an area (Do 2005, Ling 2006).

Buxton (2007) identified key characteristics of sketches where they are quick, timely, inexpensive, disposable, plentiful and ambiguous. For industrial designers, sketches are used to represent visual thoughts for communication, to generate open-ended solutions and as a means to assess ideas (Rodriguez 1992, Ehrlenspiel and Dylla 1993, Fish 1996). In contrast, engineering designers do not use sketches to express an idea for realism, but as a means to solve mechanical and production issues and to generate closed solutions (Tovey 1989, Yang and Cham 2007).

In categorising sketches, several authors including Pipes (2007) broadly grouped them as thematic sketches that emphasised aesthetic qualities; or package-constrained sketches that are bound with fixed dimensions. Other researchers (Ullman et al. 1990, Ferguson 1992, Van der Lugt 2005) 
classified thinking sketches for problem solving; prescriptive sketches for providing instructions; talking sketches for discussion; and storing sketches that retain ideas. Similarly, Olofsson and Sjölén (2005) grouped investigative sketches for problem definition; explorative sketches for generating and evaluating solutions; explanatory sketches that describe and communicate the design; and persuasive sketches that sell an idea. For clarity and consistency, this paper shall classify sketches as personal, shared, persuasive and handover sketches, each of which is now described.

\subsubsection{PERSONAL SKETCHES}

Personal sketches are two-dimensional VDRs that employ freehand marks on paper for private use. They are often created spontaneously in large volumes usually in monochrome and show only key elements of the design on paper. The group of personal sketches comprise of idea sketches, study sketches, referential sketches and memory sketches. The purpose of an idea sketch (Figure 3) is to allow the developer to externalise his thoughts quickly and to show how the design looks on paper; while a study sketch (Figure 4) is used to develop and investigate the appearance and visual impact of the idea, employing aspects of geometry, proportion, scale, layout and mechanism, etc.

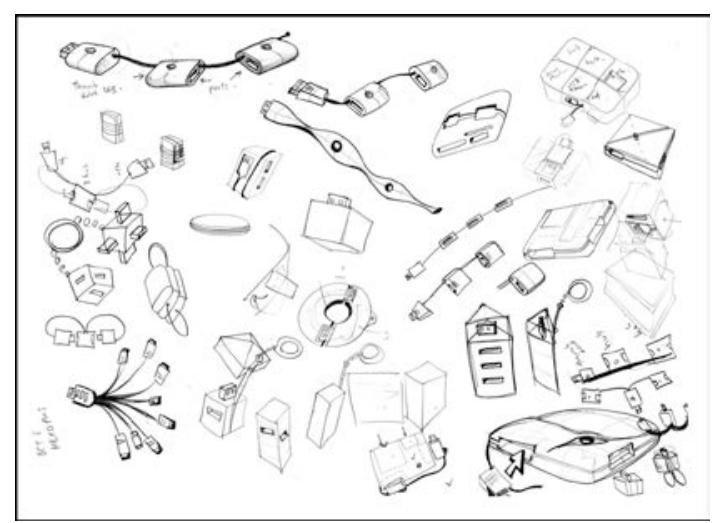

Figure 3: An idea sketch 


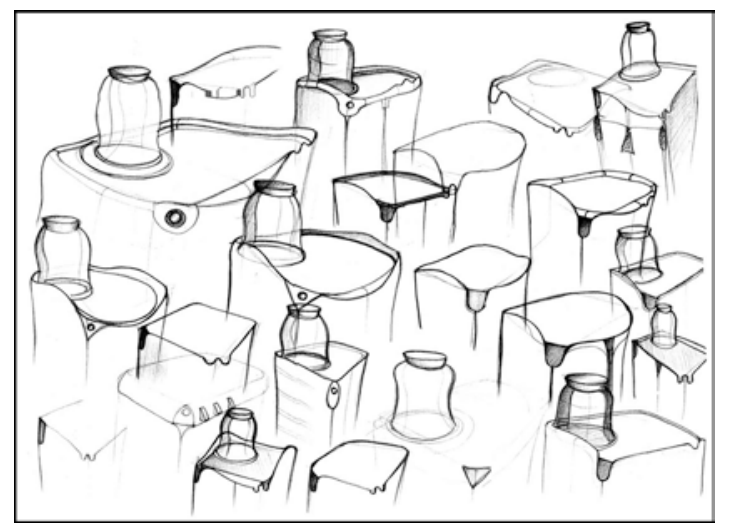

Figure 4: A study sketch

The purpose of a referential sketch (Figure 5) is to record observations for future reference or as a metaphor; while memory sketches (Figure 6) are used to help users recall thoughts and elements from previous work with the help of mind-maps, notes and text annotations.

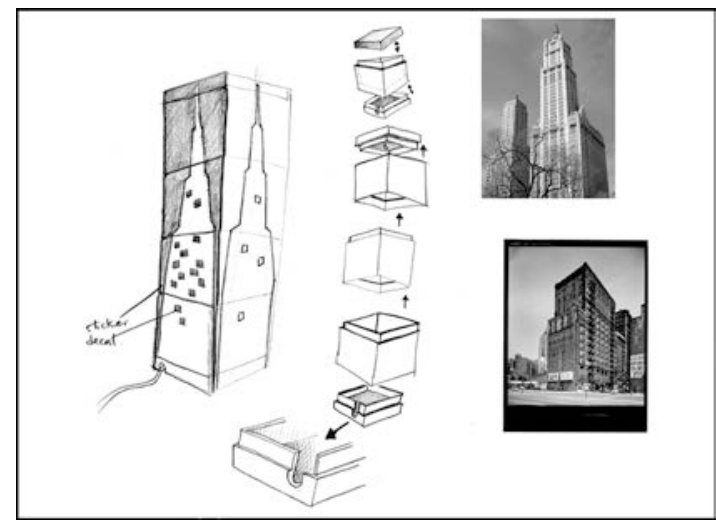

Figure 5: A referential sketch

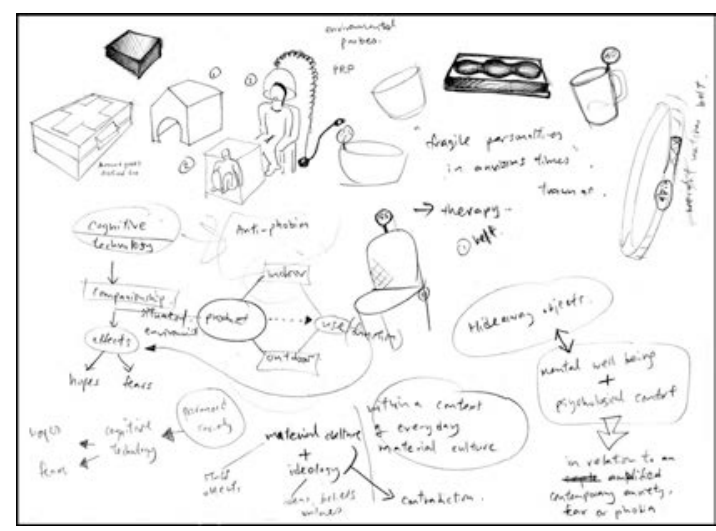

Figure 6: A memory sketch 


\subsubsection{SHARED SKETCHES}

The aim of shared sketches is to convey information to others clearly and precisely. They encourage discussion and build a common understanding of the design idea amongst the team. Text annotations and colour are often used so as to structure and define information concerning the product. The group of shared sketches comprise of coded sketches and information sketches. Coded sketches (Figure 7) employ the use of symbols to illustrate a principle or a scheme; while information sketches (Figure 8) aim to convey the design intent across the group by including annotations and key information in a graphical setting.

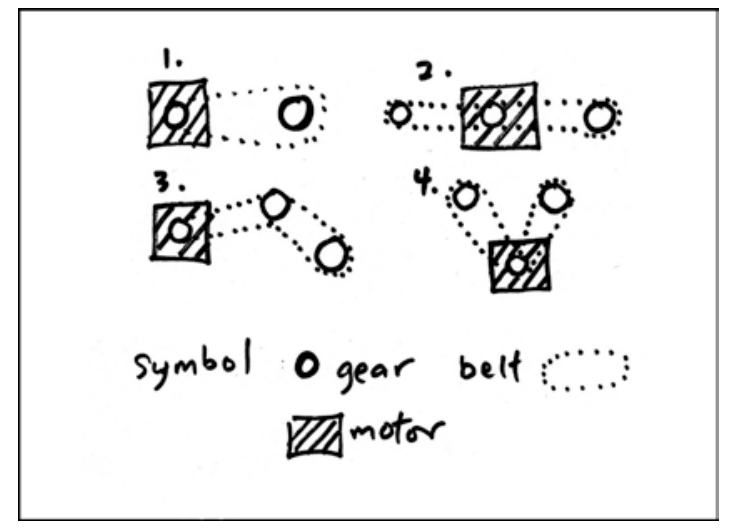

Figure 7: A coded sketch

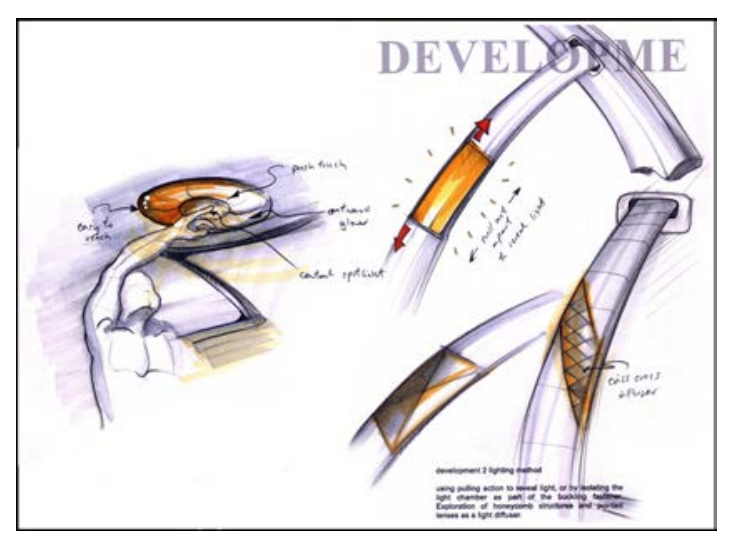

Figure 8: An information sketch 


\subsubsection{PERSUASIVE SKETCHES}

This group of sketches refer to realistic representations created in full colour, illustrating what the final product would look like. The high level of realism reduces ambiguity and enables the viewer to better understand key features of the design. Persuasive sketches comprise of renderings (Figure 9) and inspiration sketches (Figure 10). Renderings show formal proposals of design concepts employing the use of colour, tone and detail for realism; whereas inspiration sketches are more form-orientated, used to communicate the look or feel of a product by setting the tone of a design, brand or a product range. Both sketches are used as a selling tool to help stakeholders and clients to visualise and evaluate the design proposal.

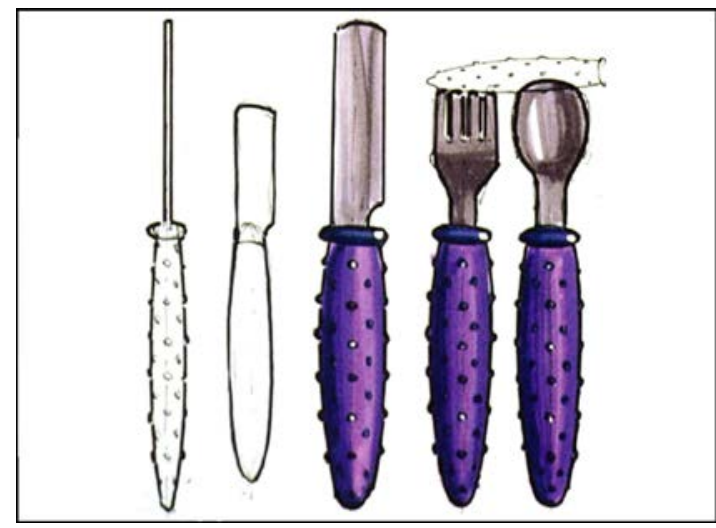

Figure 9: A rendering



Figure 10: An inspiration sketch 


\subsubsection{HANDOVER SKETCHES}

The aim of handover sketches is to convey the required information to another member of the development team. Representations in this group include prescriptive sketches that serve as a preliminary technical drawing to provide information for creating a model or a prototype. They are created during the development stages of the design process prior to a more detailed general arrangement drawing, showing key dimensions in a freehand orthographic projection drawn to scale (Figure 11).

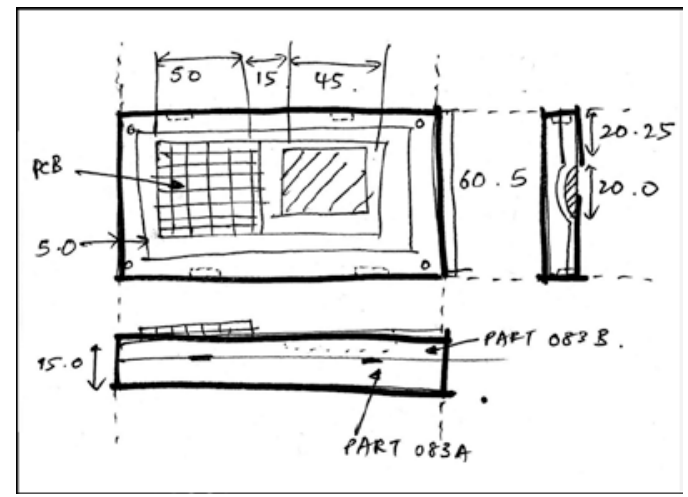

Figure 11: A prescriptive sketch

A summary of the various types of sketches discussed in this section is shown in Table 2. 


\begin{tabular}{|c|c|c|c|c|c|}
\hline \multirow{10}{*}{ 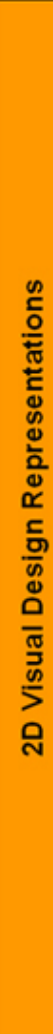 } & \multirow{10}{*}{ 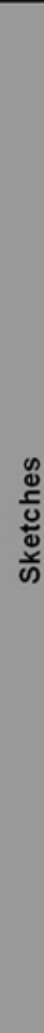 } & Sub-group & $\begin{array}{l}\text { Visual Design } \\
\text { Representation }\end{array}$ & Definition & $\begin{array}{c}\text { Visual } \\
\text { Example }\end{array}$ \\
\hline & & \multirow{4}{*}{$\begin{array}{l}\text { Personal } \\
\text { Sketches }\end{array}$} & Idea Sketch & $\begin{array}{l}\text { Idea sketches are 2D visual design representations used at a } \\
\text { personal level for externalizing thoughts quickly and to show } \\
\text { how the design looks as a physical object. }\end{array}$ & \\
\hline & & & Study Sketch & $\begin{array}{l}\text { Study sketches are 2D visual design representations used for } \\
\text { investigating the appearance and visual impact of ideas such } \\
\text { as aspects of geometric proportion, configuration, scale, layout } \\
\text { and mechanism. }\end{array}$ & \\
\hline & & & Referential Sketch & $\begin{array}{l}\text { Referential sketches are } 2 \mathrm{D} \text { visual design representations } \\
\text { used as a diary to record observations for future reference or } \\
\text { as a metaphor. }\end{array}$ & \\
\hline & & & Memory Sketch & $\begin{array}{l}\text { Memory sketches are 2D visual design representations that } \\
\text { help users recall thoughts and elements from previous work } \\
\text { with notes and text annotations. }\end{array}$ & \\
\hline & & \multirow{2}{*}{$\begin{array}{l}\text { Shared } \\
\text { Sketches }\end{array}$} & Coded Sketch & $\begin{array}{l}\text { Coded sketches are 2D visual design representations that } \\
\text { categorise information to show an underlying principle or a } \\
\text { scheme. }\end{array}$ & \\
\hline & & & Information Sketch & $\begin{array}{l}\text { Information sketches are 2D visual design representations that } \\
\text { allow stakeholders to understand the designer's intentions by } \\
\text { explaining information clearly and to provide a common } \\
\text { graphical setting. }\end{array}$ & \\
\hline & & \multirow{2}{*}{$\begin{array}{l}\text { Persuasive } \\
\text { Sketches }\end{array}$} & Renderings & $\begin{array}{l}\text { Renderings are 2D visual design representations showing } \\
\text { formal proposals of design concepts that involve the } \\
\text { application of colour, tone and detail for realism. }\end{array}$ & \\
\hline & & & Inspiration Sketch & $\begin{array}{l}\text { Inspiration sketches are form-orientated } 2 \mathrm{D} \text { visual design } \\
\text { representations used to communicate the look or feel of a } \\
\text { product by setting the tone of a design, brand or a product } \\
\text { range. }\end{array}$ & \\
\hline & & $\begin{array}{l}\text { Handover } \\
\text { Sketches }\end{array}$ & Prescriptive Sketch & $\begin{array}{l}\text { Prescriptive sketches are informal 2D visual design } \\
\text { representations that communicate design decisions and } \\
\text { general technical information such as dimensions, material } \\
\text { and finish. }\end{array}$ & 2 \\
\hline
\end{tabular}

Table 2: Sub-groups of sketches

\subsection{DRAWINGS}

A drawing is a formal arrangement of lines that determines a particular form (Dictionary of Art Terms 2003). When compared with sketches, drawings are more structured in order to formalise and verify aspects of the design (Herbert 1993, Robbins 1994, Goel 1995). Ullman et al. (1990) also stated that drawings are 'made in accordance with a set of rules and are drafted with mechanical instruments or CAD systems to scale'; whereas sketches are created in free-hand and are often not to scale. A formal definition was proposed by Tjalve et al. (1979) who defined drawings as the modelled properties of a design (e.g. structure, form, material, dimension, surface, etc.) and coded in terms of symbols (e.g. coordinates, graphical symbols, types of projection). Drawings serve as a record to analyse and check details, as well 
as a communication medium between the designer and the manufacturer (Ullman et al. 1988, 1990, Bucciarelli 1994). Besides the type of projection, drawings may include the use of colour and text so as to provide more information (Yang 2003, Song and Agogino 2004).

In classifying drawings, Fraser and Henmi (1994) analysed architectural drawings and grouped them as referential drawings, diagrams, design drawings, presentation drawings and visionary drawings. For this paper, drawings that are created for the key purpose of visual aesthetics are classed as industrial design drawings; while drawings created for technical use are classed as engineering drawings, although at times, the purpose of a drawing may overlap over both groups.

\subsubsection{INDUSTRIAL DESIGN DRAWINGS}

Industrial design drawings are two-dimensional representations that employ formal lines to determine a particular form and they are often drawn to scale. They comprise of concept drawings (Figure 12) that show the design proposal in colour with orthographic views and precise lines; while presentation drawings (Figure 13) are final drawings created in perspective for clients and other stakeholders to understand the product better. 


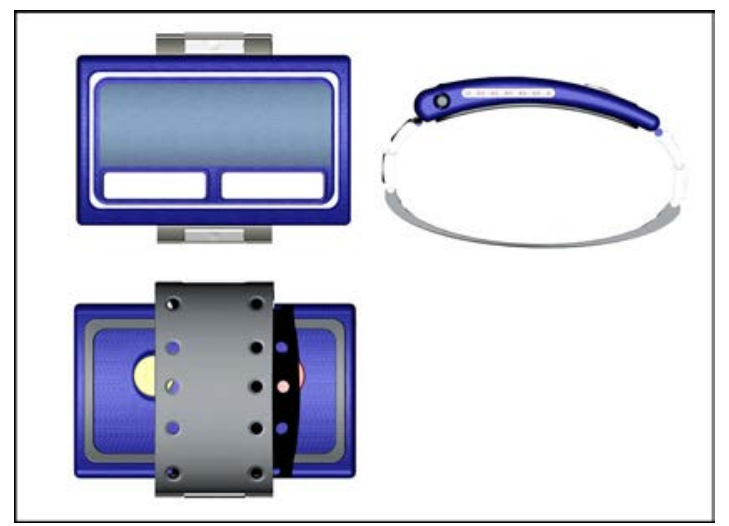

Figure 12: A concept drawing

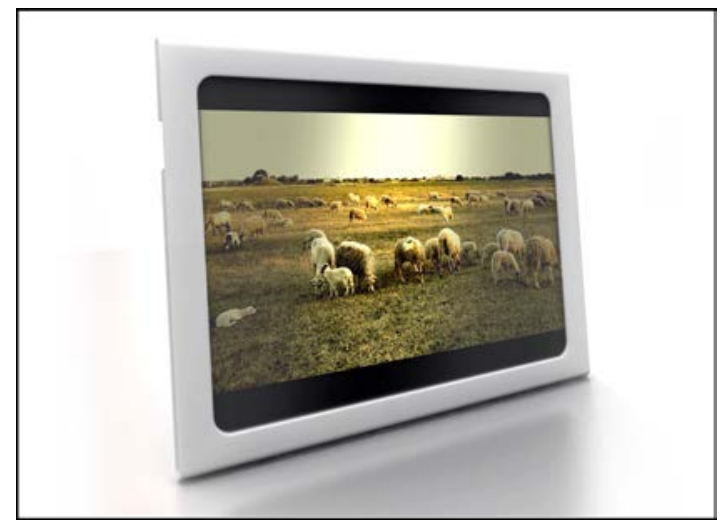

Figure 13: A presentation drawing

Another type of industrial design drawings are scenarios and storyboards (Figure 14) which are used to explain a concept by showing possible settings of a product, user or an environment. They may take the form of a time line to describe stages of a product's use.

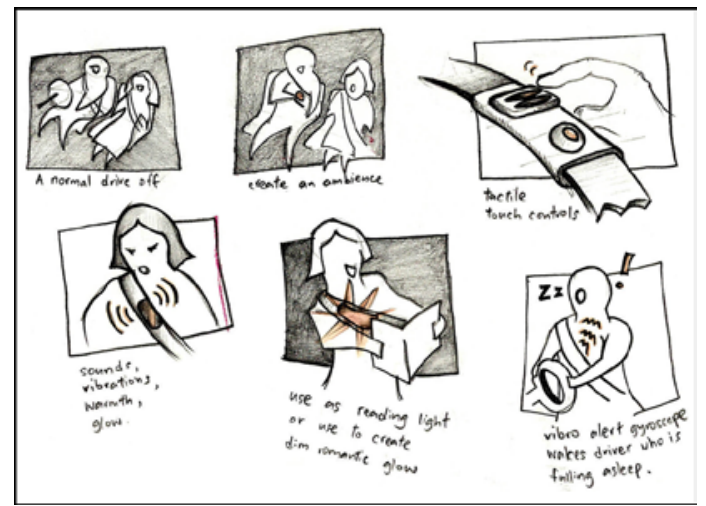

Figure 14: Scenarios and storyboards 


\subsubsection{ENGINEERING DESIGN DRAWINGS}

Engineering design drawings are concerned with representing technical information through the use of formal lines and are drawn to scale. The use of text, dimensions and other technical data provide additional information to the viewer. In the use of diagrams (Figure 15), the aesthetic form is often omitted to show the underlying principle of an idea or to represent relationships between objects.

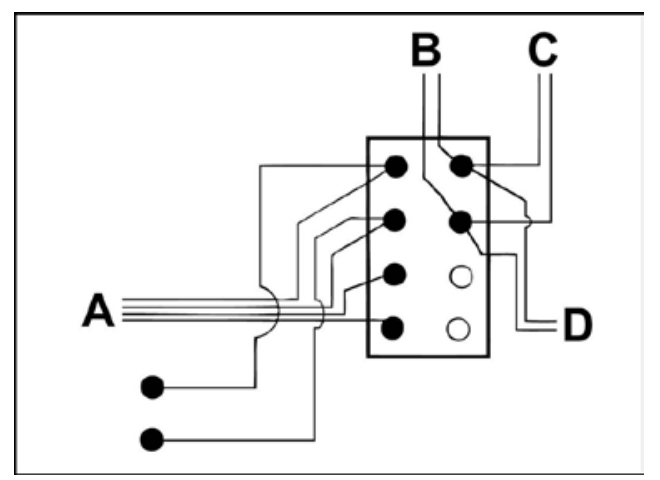

Figure 15: A diagram

Single-view drawings (Figure 16) are drawn in an axonometric projection made up of either isometric, trimetric, diametric, oblique or perspective views with very little aesthetic detail; whereas multi-view drawings (Figure 17) are representations employed through first or third angle projections. Both of these drawings are usually conveyed as an outline with little colour to describe the geometry and to show alternative arrangements. 


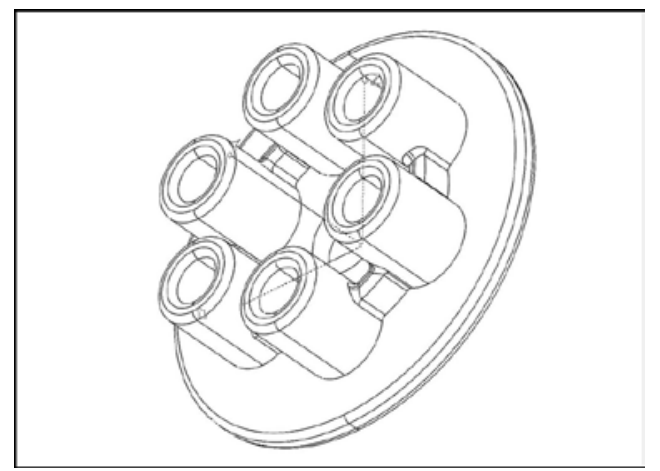

Figure 16: A single-view drawing

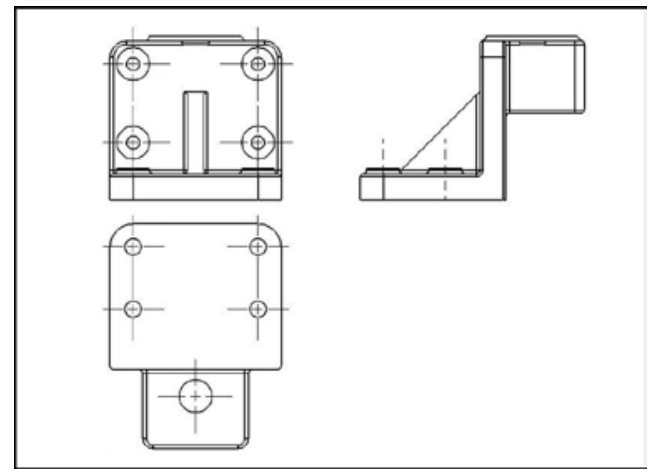

Figure 17: A multi-view drawing

A general arrangement drawing (Figure 18) is used to represent an overview of the design but omitting the internal details. They are used for the production of appearance models with limited detail; while technical drawings (Figure 19) are more formalised, complete and standardised, showing the material specification, parts list, manufacture, finish and assembly details, all of which represent the built object and covering every detail for manufacture.

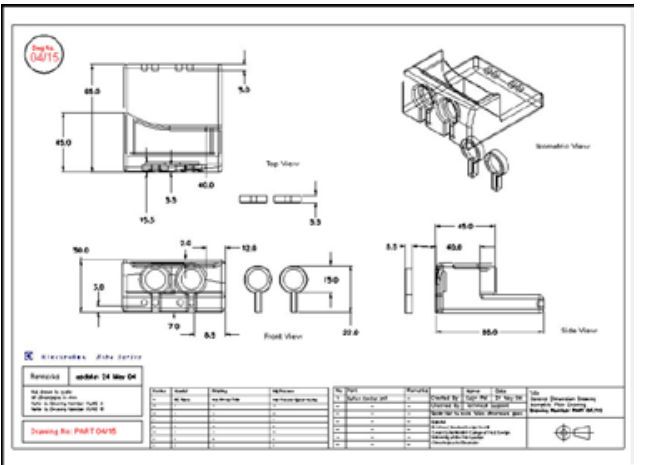

Figure 18: A general arrangement drawing 




Figure 19: A technical drawing

In contrast, technical illustrations are concerned with simplifying engineering details but without omitting important information from the product. They may also be used to show the parts of a product or how it is being used (Figure 20). In summary, engineering design drawings are two-dimensional VDRs comprising of diagrams, single-view drawings, multi-view drawings, general arrangement drawings, technical drawings and technical illustrations.

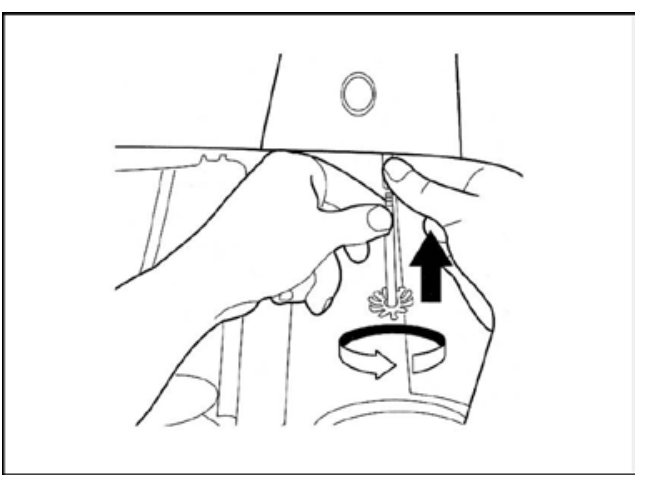

Figure 20: A technical illustration

A summary of the various types of drawings discussed in this section is shown in Table 3. 


\begin{tabular}{|c|c|c|c|c|c|}
\hline \multirow{10}{*}{  } & \multirow{10}{*}{  } & Sub-group & $\begin{array}{l}\text { Visual Design } \\
\text { Representation }\end{array}$ & Definition & Visual Example \\
\hline & & \multirow{3}{*}{$\begin{array}{l}\text { Industrial } \\
\text { Design } \\
\text { Drawings }\end{array}$} & Concept Drawing & $\begin{array}{l}\text { Concept drawings are 2D visual design representations that } \\
\text { show the design proposal in colour with orthographic views } \\
\text { and precise lines. }\end{array}$ & \\
\hline & & & Presentation Drawing & $\begin{array}{l}\text { Presentation drawings are 2D visual design representations } \\
\text { drawn in perspective that act as final drawings for clients } \\
\text { and other stakeholders. }\end{array}$ & \\
\hline & & & $\begin{array}{l}\text { Scenario and } \\
\text { Storyboard }\end{array}$ & $\begin{array}{l}\text { Scenarios and storyboards are } 2 \mathrm{D} \text { visual design } \\
\text { representations to suggest user and product interaction, and } \\
\text { to portray its use in the context of artefacts, people and } \\
\text { relationships. }\end{array}$ & \\
\hline & & \multirow{6}{*}{ 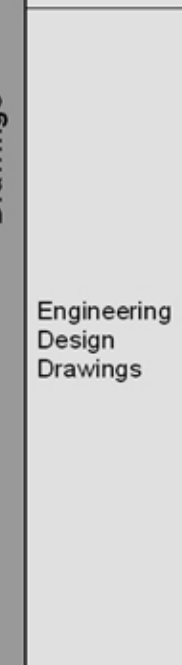 } & Diagram & $\begin{array}{l}\text { Diagrams are 2D visual design representations that show } \\
\text { the underlying principle of an idea or to represent } \\
\text { relationships between objects, represented with simple } \\
\text { geometric elements. }\end{array}$ & \\
\hline & & & Single View Drawing & $\begin{array}{l}\text { Single view drawings are 2D visual design representations } \\
\text { drawn in an axonometric projection made up of either } \\
\text { isometric, trimetric, diametric, oblique or perspective views, } \\
\text { drawn with little aesthetic detail. }\end{array}$ & \\
\hline & & & Multi View Drawing & $\begin{array}{l}\text { Multi view drawings are 2D visual design representations } \\
\text { employed through first or third angle projections. }\end{array}$ & \\
\hline & & & $\begin{array}{l}\text { General Arrangement } \\
\text { Drawing }\end{array}$ & $\begin{array}{l}\text { General arrangement drawings are 2D visual design } \\
\text { representations that embody the refined design but omit the } \\
\text { internal details. They are used for the production of } \\
\text { appearance models with limited detail. }\end{array}$ & 进- की- \\
\hline & & & Technical Drawing & $\begin{array}{l}\text { Technical drawings are formal 2D visual design } \\
\text { representations used to define, specify and graphically } \\
\text { represent the built object and to cover every detail for } \\
\text { manufacture. }\end{array}$ & $\sqrt{2} \Rightarrow$ \\
\hline & & & Technical Illustration & $\begin{array}{l}\text { Technical illustrations are 2D visual design representations } \\
\text { that simplify the engineering details and highlight key } \\
\text { features without omitting important information from the } \\
\text { product. }\end{array}$ & \\
\hline
\end{tabular}

Table 3: Sub-groups of drawings

\subsection{MODELS}

According to Holmquist (2005), models are non-functional objects used to describe the visual appearance of an intended product. However, Buur and Andreasen (1989) cited that they can also be used to reproduce the rough functional properties of a product. Models are used because two-dimensional sketches and drawings are often inadequate to explain the three-dimensional attributes of an object (Tovey 1997). The three-dimensional properties of a model allow both industrial designers and engineering designers to explain the function, performance and aesthetic aspects of a design, enabling them to 'describe, visualise and sculpture thoughts' (Buur and Andreasen 1989), and to 'develop, reflect, and communicate design ideas with others' (Peng 1994). However, Garner (2004) pointed out that some models were more suitable for 
communicating information, while others were better suited for testing ideas. A full size or scaled down physical model allows feedback from stakeholders and addressing issues before committing to tooling or manufacture in order to minimise downstream mistakes (Powell 1990). They are useful to show how components are integrated so that clients may visualise the product better (Woodtke 2000). Models further allow the developer to gain tactile clues, as described by Smyth (1998) as 'designers thinking with their hands'. Although rough models are fast to produce and are suitable for creative work, they may sometimes contain very limited information. Conversely, detailed models can be labour-intensive. Therefore, simple models are used during early stages of design where ideas and development take place; whereas detailed models are used when the concept has been confirmed. Veveris (1994) also acknowledged the trend whereby 'the complexity, cost and functional capabilities of models increase with the progress of product development'. For this research, models created for the purpose of aesthetics, ergonomics and other design related aspects are classed as industrial design models; while those for functional and technical development are classed as engineering models although the purpose of a model may at times overlap over both categories.

\subsubsection{INDUSTRIAL DESIGN MODELS}

Industrial design models are three-dimensional VDRs used to reproduce the physical attributes of an intended product in a tangible form. They emphasise

the visual aesthetics and form of a product without having any functional features. The group of industrial design models comprise three-dimensional 
sketch models, design development models and appearance models. 3D sketch models (Figure 21) offer an affordable and quick way to physically represent potential ideas from $2 \mathrm{D}$ sketches or drawings into a tangible medium, as well as to obtain visual feedback.

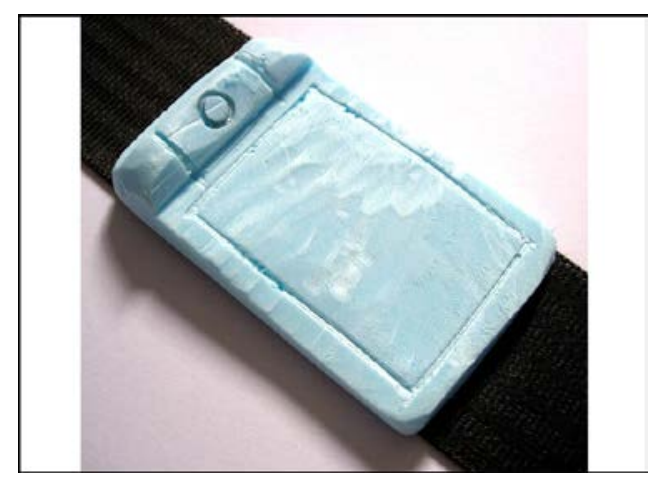

Figure 21: A 3D sketch model

Design development models (Figure 22) are used to refine shapes, to investigate how components are assembled and for testing purposes. In contrast, appearance models (Figure 23) enable stakeholders and clients to obtain a realistic outlook of the product but without having any working mechanisms.

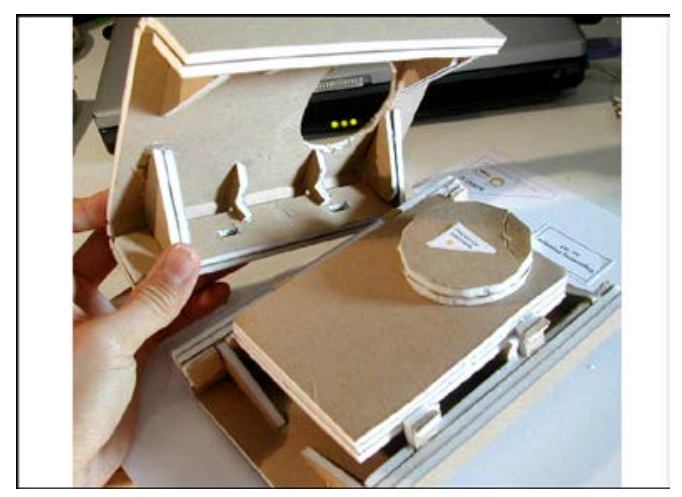

Figure 22: A design development model 


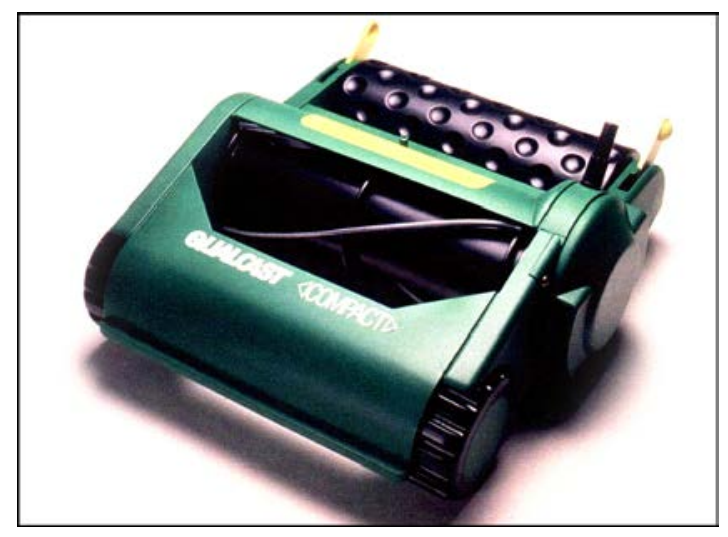

Figure 23: An appearance model

\subsubsection{ENGINEERING DESIGN MODELS}

Engineering design models are three-dimensional VDRs used to represent the technical aspects of a product. They comprise of functional concept models, concept of operation models, production concept models, assembly concept models and service concept models. Functional concept models (Figure 24) highlight important functional parameters including aspects of yield and performance. In contrast, concept of operation models (Figure 25) help communicate the understanding of operation and its use. Both models are often mechanical-looking and do not have the aesthetic outlook of the final product.

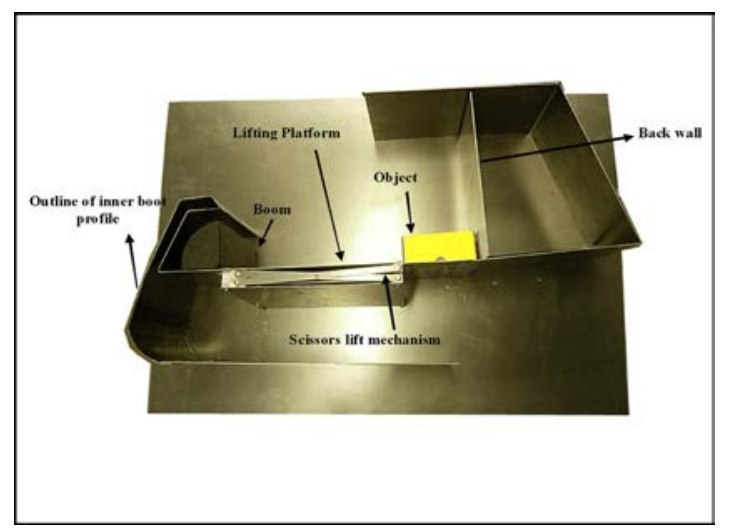

Figure 24: A functional concept model 


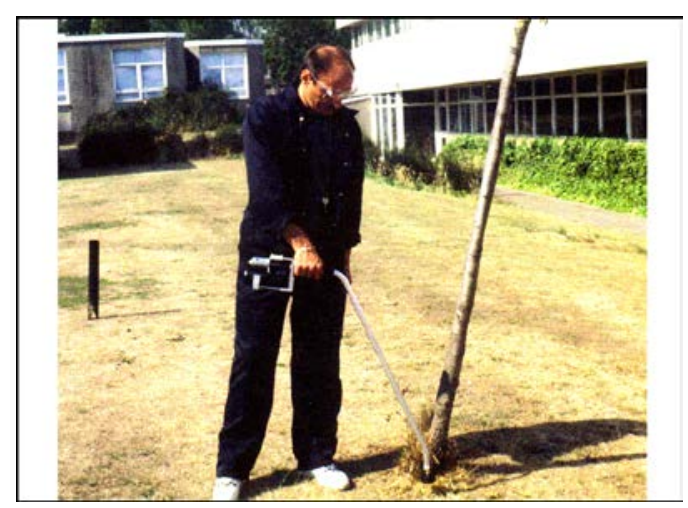

Figure 25: A concept of operation model

Production concept models (Figure 26) are used to help assist the evaluation of production processes or for manufacturing production. Assembly concept models (Figure 27) are used to show the relationship of parts in terms of assembly and cost. Lastly, service concept models (Figure 28) are used to illustrate how the product may be serviced or maintained.



Figure 26: A production concept model

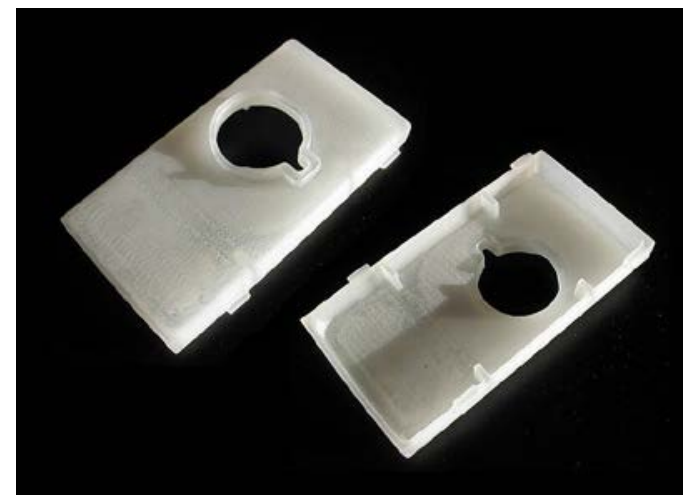

Figure 27: An assembly concept model 


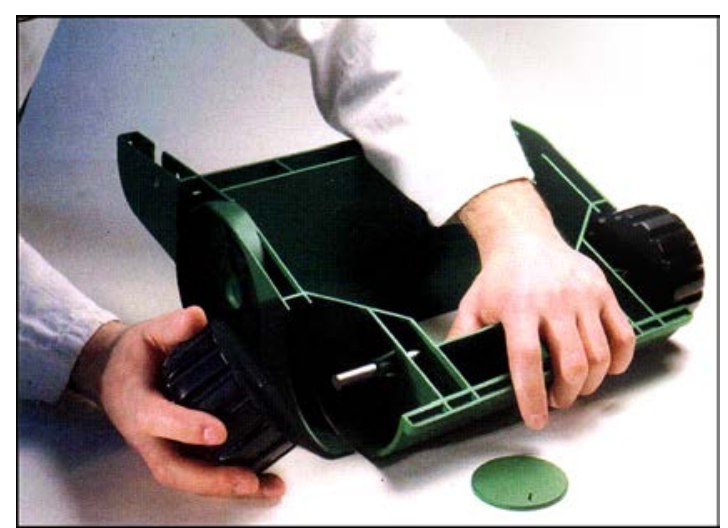

Figure 28: A service concept model

A summary of the various types of models discussed in this section is shown in Table 4.

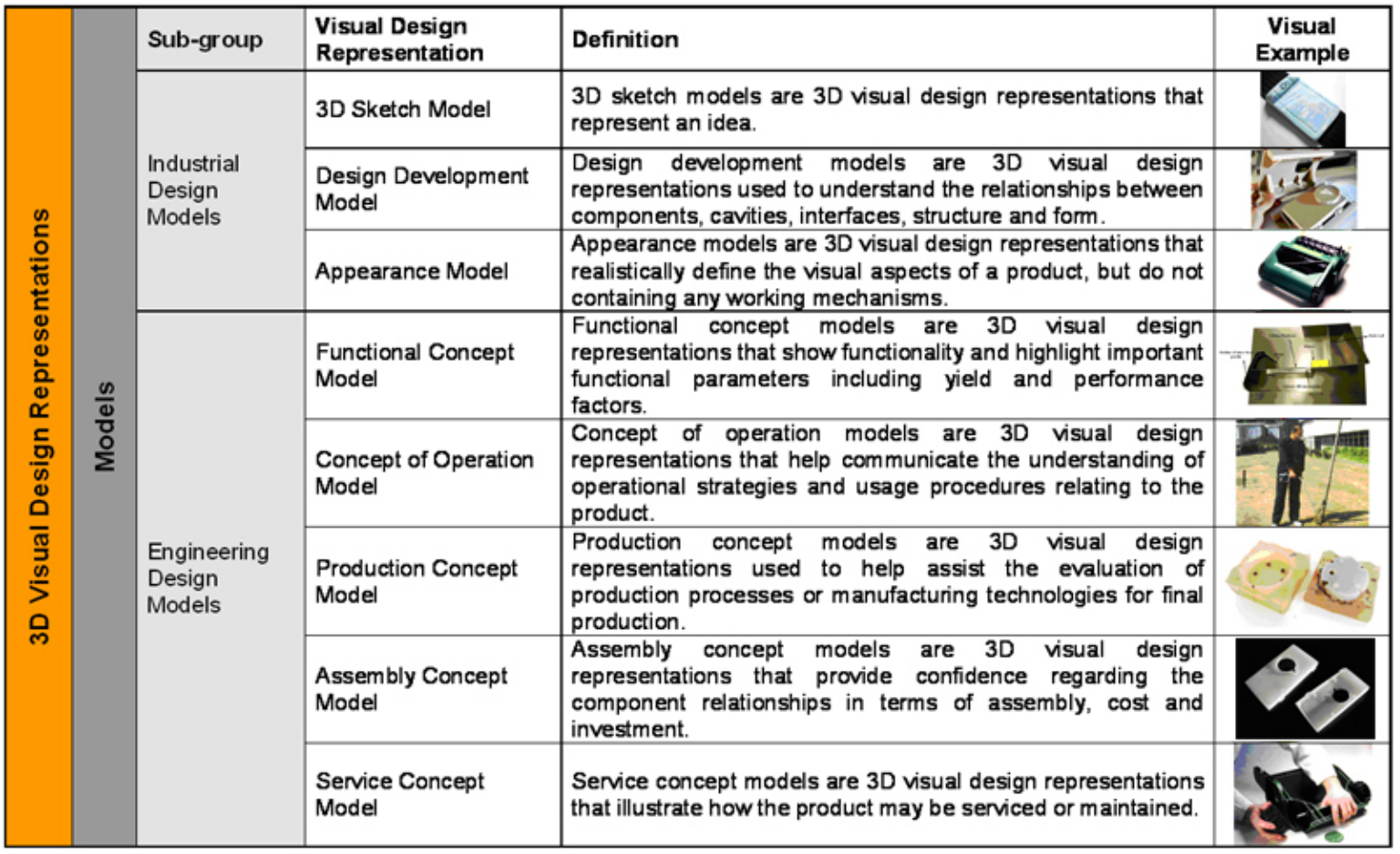

Table 4: Sub-groups of models

\subsection{PROTOTYPES}

The aim of prototyping is to produce information for design processes and

design decisions, as well as to communicate and verify the final design 
(Kurvinen et al. 2008). According to Holmquist (2005), prototypes only consist of functional parts and do not resemble a final product, whereas other researchers (Luzadder 1975, Author 1992) defined them as full-scale physical representations, and Best (2006) considered prototypes as being in either a physical or virtual form. According to Houde and Hill (1997), they defined a prototype broadly as any representation of a design idea and further classified them into role prototypes, look and feel prototypes, implementation prototypes and integration prototypes. They go on to add that the selection of a prototype depends on its intended function and what features are required. For this paper, the term 'prototype' refers to three-dimensional VDRs that incorporate working and functional components and are often built to full scale.

Kelly (2001) described prototypes as being 'worth a thousand pictures', serving as a tangible artefact providing confidence to stakeholders about the final design. With a physical representation, stakeholders can interact and finalise aspects of the design (Bødker and Buur 2002, Preece et al. 2002). It brings the perspectives of multi-disciplinary team members together and provides a medium to help joint decisions to be made and for refinements to be conducted safely and cheaply (Kolodner and Wills 1996). Otto and Wood (2001) stated that multi-disciplinary members used prototypes differently according to their needs. Industrial designers used prototypes to investigate the look and feel of a design, while engineering designers used them to analyse functional properties. As a physical working representation of a design proposal, prototypes are used to test the feasibility of the finalised concept, for customer assessment and to clarify production and technical issues (Holbrook and Moore 1981, Finn 1985). Yang and Daniel (2005) added 
that the process of constructing prototypes itself allows developers to understand issues first hand in a way that cannot be gained from sketches or drawings. Models are better suited during the early stages of development for problem solving and idea generation, whereas prototypes are employed towards the later stages to confirm and evaluate the aesthetics, ergonomics and performance of the design (Ullman 2003, Frishberg 2006). As an integration medium, prototypes show how the components fit together and to detect discrepancies. In terms of milestones, they serve as a physical goal demonstrating that a level of progress in product development has been met. Prototypes are also used by manufacturers to confirm the tooling, for cost analysis and as a promotional material. In addition, Ulrich and Eppinger (2003) identified a pattern whereby products with high technical or market risks tend to require more prototypes to be built and tested. For this research, prototypes are classified as industrial design prototypes and engineering design prototypes. In the former, they are created to finalise the aesthetics, ergonomics and other design related aspects; while the latter is used to test, evaluate and validate the functional and technical aspects of the final design. Similar to other VDRs, the purpose of a prototype may at times overlap over both groups.

\subsubsection{INDUSTRIAL DESIGN PROTOTYPES}

Industrial design prototypes are three-dimensional VDRs that reproduce the final form, ergonomics and design related aspects of the product. Industrial design prototypes comprise appearance prototypes, alpha prototypes, beta prototypes and pre-production prototypes. Appearance prototypes (Figure 29) are highly detailed, full-scale 3D representations that combine the functional 
and aesthetical aspects of a product, while alpha prototypes (Figure 30) are used to verify the outlook and construction of sub-systems that have been technically proven and fabricated using the actual materials. In contrast, beta prototypes (Figure 31) are full-scale and fully-functional representations that are used to examine how the product would be used in its intended environment. On the other hand, pre-production prototypes (Figure 32) are generally concerned with verifying aspects of the design, reviewing the resolved features and to ensure that the quality from an initial batch production is satisfactory.



Figure 29: An appearance prototype

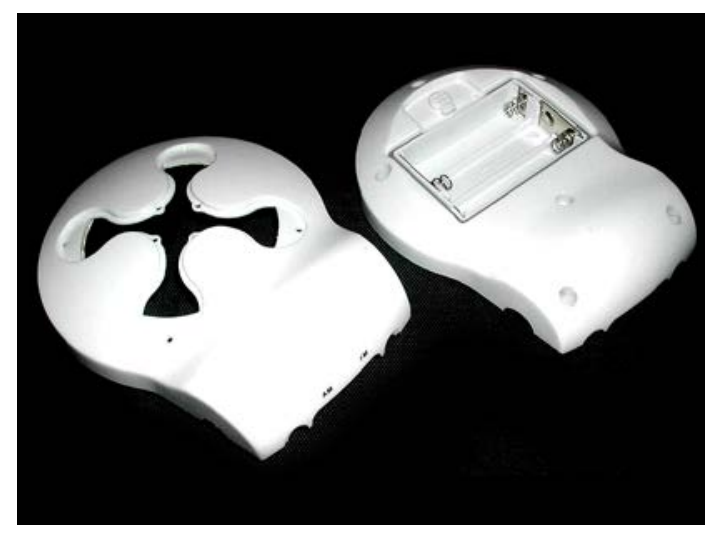

Figure 30: An alpha prototype 


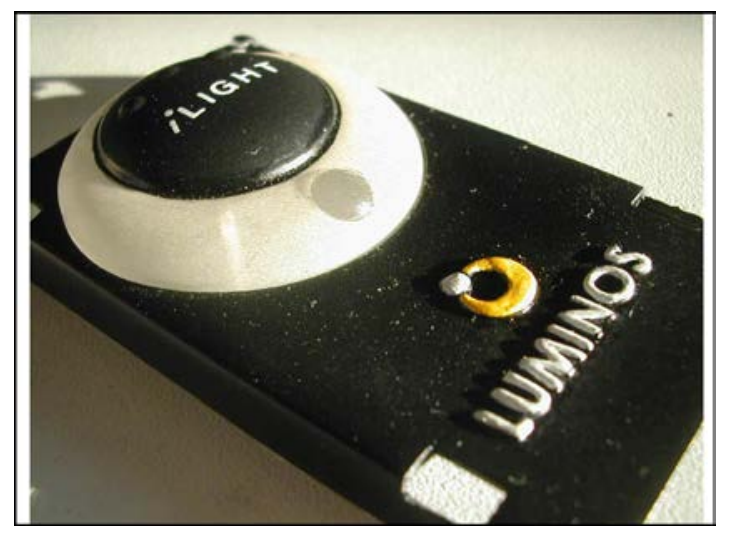

Figure 31: A beta prototype

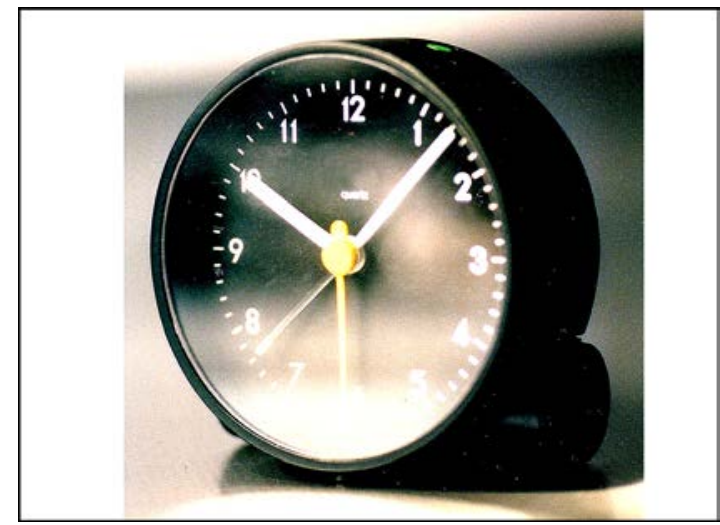

Figure 32: A pre-production prototype

\subsubsection{ENGINEERING DESIGN PROTOTYPES}

Engineering design prototypes are three-dimensional VDRs that are concerned with the technical aspects of the design. Engineering design prototypes comprise experimental prototypes, system prototypes, final hardware prototypes, tooling prototypes and off-tool prototypes. Experimental prototypes (Figure 33) are used to parameterise the layout of a product and to replicate the actual product's physics; whereas system prototypes (Figure 34) combine the various components of the product in order to test and assess functional aspects of mechanics and performance as an overall system. Final hardware prototypes (Figure 35) are used to validate and refine aspects of product and material fabrication, as well as to solve other assembly issues. 


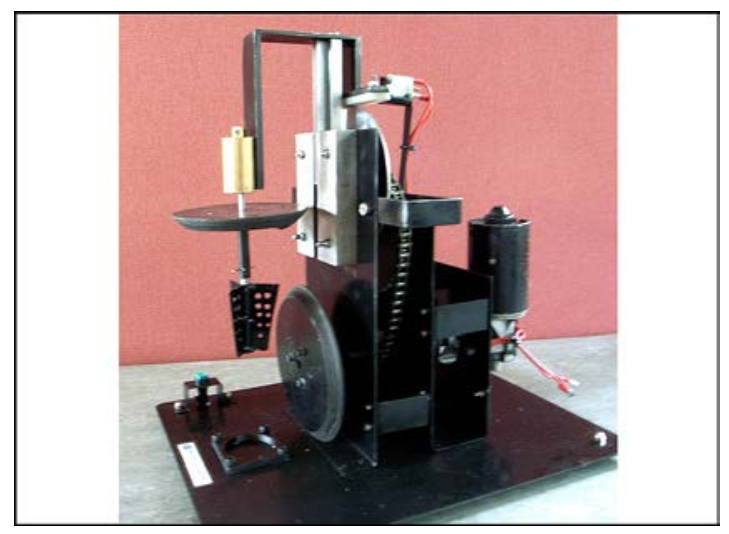

Figure 33: An experimental prototype

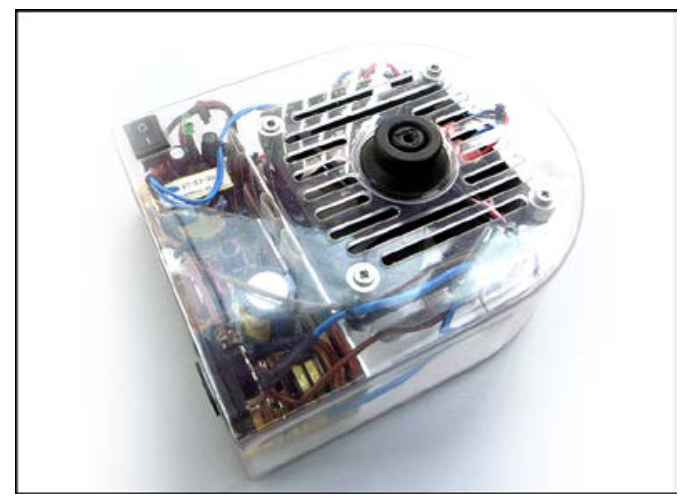

Figure 34: A system prototype

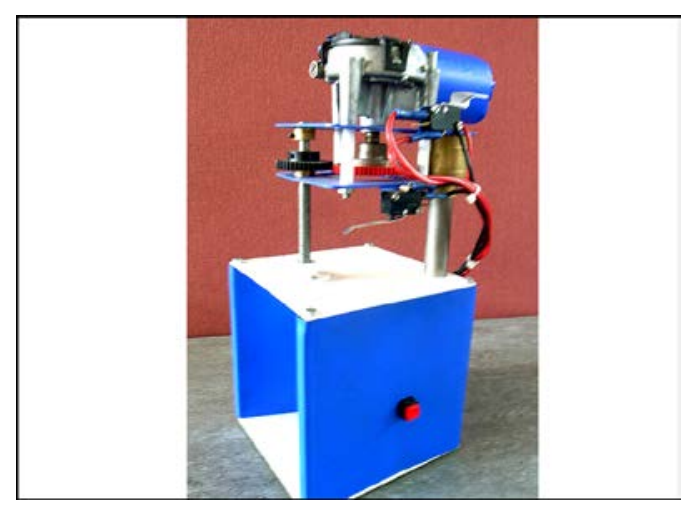

Figure 35: A final hardware prototype

Tooling prototypes (Figure 36) are used to assist in the fabrication of the actual tooling, so as to enable potential problems to be intercepted before discrepancies in form or fit occur. Lastly, off-tool prototypes (Figure 37) consist of the physical components produced from the actual tooling and 
materials intended for the final product. They are used as a final check to ensure that the production parts are satisfactory prior to mass manufacturing.

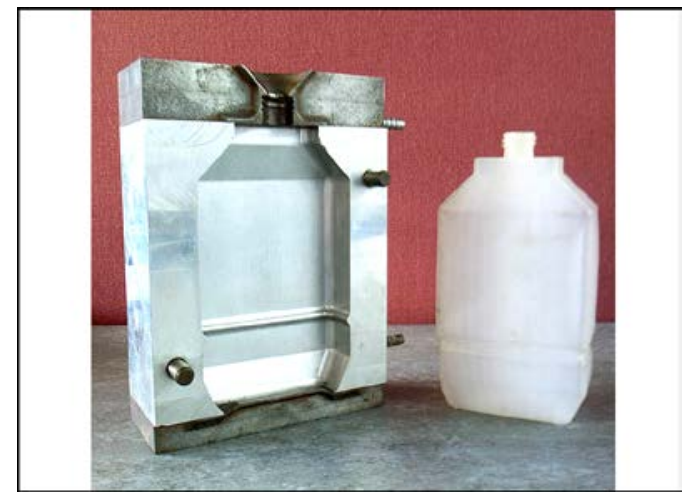

Figure 36: A tooling prototype

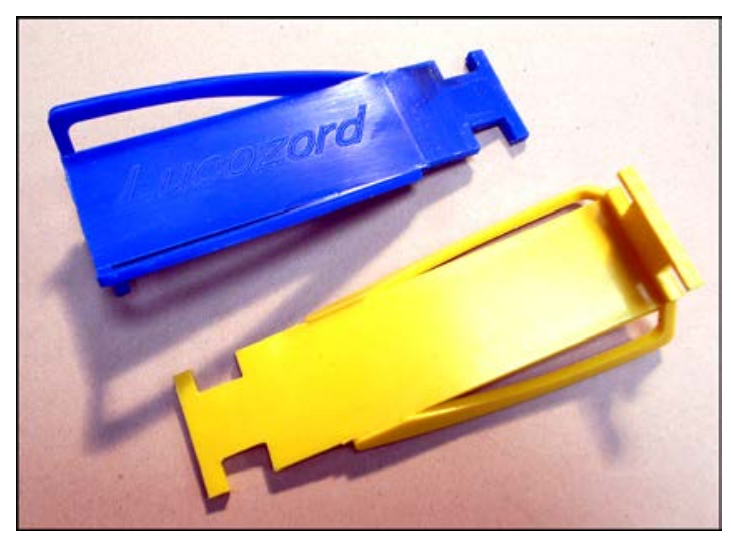

Figure 37: An off-tool prototype

A summary of the various types of prototypes discussed in this section is shown in Table 5. 




Table 5: Sub-groups of prototypes

\section{VALIDATION}

Validation was undertaken by presenting the taxonomy to 43 respondents with an accompanying booklet that described each of the 35 representations in detail. The survey took place from the period of May to October 2007. The participants were practitioners or academics with at least 3 years of work experience from their industry. In total, the survey involved 17 industrial designers, 14 engineering designers, 4 project managers and 8 academics from 23 different industrial design consultancies and academic institutions. The interview included a set of questions that aimed to examine and confirm if the 35 VDRs were all employed by industrial designers and engineering designers and if the respondents had any issues with the structure and content of the taxonomy. The interviews took place in the United Kingdom and 
in Singapore in order to obtain feedback from Eastern and Western design practitioners and academics. All the respondents (100\%) were supportive of the content and structure of the taxonomy. Of the 43 respondents, 42 of them commented that the taxonomy would provide them with a more complete and structured understanding of the design representations employed by industrial designers and engineering designers. In addition, 14 of the respondents (32.6\%) felt that the provision of a thumbnail image supported the definition of each taxon. Following the first stage of the validation, every opportunity was taken to continually update and improve the clarity and graphic design of the classification.

To further validate the findings of the first survey, the same taxonomy was presented to a different audience by the authors during a seminar at the 2009 Industrial Designers Society of America (IDSA) International Conference held in Miami, USA. The seminar was attended by 20 experienced design practitioners and educators from a global community. A verbal presentation with visual aids described each of the 35 VDRs in detail and the classification was presented in the form of the taxonomy. The attendees were also provided with a printed checklist that included a name, description and colour image for each of the taxons. The checklist also contained a box that could be ticked to indicate the validity of each taxon. A semi-structured discussion followed the presentation with feedback indicating a high level of support for the aims and content of the taxonomy. There was a consensus for a general need for the taxonomy to be made available to educators and practitioners in a suitable format. 
Attendees were then asked to reflect on the seminar presentation/discussion and return the completed checklist by the end of the conference. Although 20 forms were handed out at the seminar (1 to each attendee), only 7 (35\%) were returned at the end of the conference. Although the return rate was relatively low, no issues were identified in the returned checklists. The triangulation of results obtained from both stages of the validation (interview and seminar/checklist) gives a high degree of confidence in the taxonomy as a valid means of presenting different types of VDRs that are widely recognised by designers from around the world.

\section{CONCLUSION}

This paper has described the importance of an inclusive taxonomy that has compiled and categorised VDRs employed by industrial designers and engineering designers during NPD. It is hoped that by having a common ground and a consistent understanding of design representations, multidisciplinary members are able to better achieve more effective working processes. In addition, characterising and cross-referencing design representations would allow both disciplines to learn from each other, thereby enriching the understanding of their distinctive work approaches.

This taxonomy has been developed by means of orthogonality, where each classification is distinctive from that of other taxons. Broad spanning has been achieved by conducting a thorough review of the literature and representing the most significant representations in the taxonomy. From a survey of the literature, the representations were classified into four taxons consisting of sketches, drawings, models and prototypes being established as the top-level 
categories and further expanded downwards with its sub-categories. Next, precision and usability of the taxonomy has been accomplished by ensuring a clear and structured layout with the use of visual images as examples. Finally, the taxonomy was subjected to an interview survey involving 43 respondents, as well as the use of a checklist which was handed out at an international design conference by means of a second validation. There were no issues raised concerning the taxonomy or with the 35 representations.

The taxonomy of Visual Design Representations is suggested as a useful aid in the broader objective of achieving more effective use of representations by industrial designers and engineering designers. Through an understanding of the taxonomic relationships, it is hoped that the classification will be able to help industrial designers and engineering designers (as well as other stakeholders involved in NPD) decide how to represent various kinds of information, and in recognising the limitations of each VDR when conveying information. It is also anticipated that the taxonomy will be useful in supporting the development of further collaboration tools and also for developing and expanding existing research. A key direction for further work would be to subject this taxonomy to a more thorough empirical survey for enhanced validation. 


\section{REFERENCES}

Alisantoso, D., Khoo, L. P., Lee, I. B. H., Lu, W. F. (2006). "A design representation scheme for collaborative product development." International Journal of Advanced Manufacturing Technology(No. 30).

Bairstow, J., Barber, R., Kenny, M. (1999). Design Modelling - Visualising Ideas in 2D and 3D. London, Hoddeer \& Stoughton.

Baskinger, M. (2008). "Pencils Before Pixels: A Primer in Hand-Generated Sketching." Interactions March - April.

Best, K. (2006). Design Management - Managing Design Strategy, Process and Implementation. Switzerland, AVA Publishing SA.

Bødker, S. and J. Buur (2002). "The Design Collaboratorium - A Place for Usability Design." ACM Transactions on Computer- Human Interaction Vol. 9(No. 2): pp. 152-169.

Botturi, L., and Stubbs, S. T. (2008) Handbook of Visual Languages for Instructional Design: Theories and Practices. Idea Group Inc.: Hershey, PA.

Boujut, J. F. and P. Laurillard (2002). "A co-operation framework for product process integration in engineering design." Design Studies(No. 23).

Bucciarelli, L. (1994). Designing engineers. Cambridge, MA, MIT Press.

Buur, J. and M. M. Andreasen (1989). "Design models in mechatronic product development." Design Studies Vol. 10(No. 3): pp. 155- 162.

Buxton, B. (2007). Sketching User Experiences - Getting the design right and the right design. San Francisco, Morgan Kaufmann.

Cain, R. E. (2005). Involving users in the Design Process: The Role of Product Representations in Co-Designing (PhD Thesis). Department of Design and Technology. Loughborough, Loughborough University.

Concise Oxford Dictionary (1999). The Concise Oxford Dictionary. New York, USA, Oxford University Press Inc.

Cross, N. (1999). "Natural intelligence in design." Design Studies Vol. 20(No. 1): pp. 25-39.

Derr, R. (1973). "A Taxonomy of social purposes of public schools". New York: McKay Publishing. Quoted in: Ostergaard K. and Summers, J. (2009) "Development of a Systematic Classification and Taxonomy of Collaborative Design Activities" Journal of Engineering Design Vol. 20 No. 1.

Dictionary of Art Terms (2003). Dictionary of Art Terms. Thames and Hudson World of Art. E. Lucie-Smith (Ed.). London, Thames and Hudson. 
Do, E. Y.-L. (2005). "Design sketches and sketch design tools." KnowledgeBased Systems(No. 18): pp. 383-405.

Do, E. Y.-L., Gross, M. D., Neiman, B., Zimring, C. (2000). "Intentions in and relations among design drawings." Design Studies Vol. 21(No. 5).

Eckert, C. and J.-F. Boujut (2003). "The Role of Objects in Design CoOperation: Communication through Physical or Virtual Objects." Computer Supported Cooperative Work(No. 12): pp. 145-151.

Ehrlenspiel, K. and N. Dylla (1993). "Experimental Investigation of Designers' Thinking Methods and Design Procedures." Journal of Engineering Design Vol. 4(No. 3).

Eissen, K. and R. Steur (2008). Sketching: Drawing Techniques for Product Designers. Singapore, Bis Publishers / Page One Publishing.

Engelbrektsson, P. and M. Soderman (2004). "The use and perception of methods and product representations in product development: a survey of Swedish industry." Journal of Engineering Design Vol. 15(No. 2).

Erhorn, C. and J. Stark (1994). Competing by Design - Creating Value and Market Advantage in New Product Development. Vermont, Oliver Wight Publications, Inc.

Author (1992). Model or prototype which, when and why? IDATER 1992 Conference, Loughborough University (Design and Technology).

Author (2002) The Integration of Rapid Prototyping within Industrial Design Practice (Staff Thesis) Department of Design and Technology. Loughborough, Loughborough University.

Ferguson, E. S. (1992). Engineering and the mind's eye. Cambridge, Massachusetts, MIT Press.

Finn, A. (1985). "A theory of the consumer evaluation process for new product concepts," Research in Consumer Behaviour Vol. 1 pp. 35-65. Quoted in: Söderman, Mikael (2002) "Comparing Desktop Virtual Reality with handmade sketches and real products: Exploring key aspects for end-users' understanding of proposed products," Journal of Design Research Vol. 2 No. 1.

Fish, J. C. (1996). "How Sketches Work-A Cognitive Theory for Improved System Design," PhD dissertation: Loughborough University of Technology. Quoted in: Do, Ellen Yi-Luen (2005) "Design sketches and sketch design tools," Knowledge-Based Systems No. 18 pp. 383-405.

Fiske, J. (1998). "Kommunikationsteorier: en introduktion," Wahlström och Widstrand, Centraltryckeriet, Borås. Quoted in: Persson, Sara and Warell, Anders (2003) "Relational Modes between Industrial Design and Engineering 
Design - a Conceptual Model for Interdisciplinary Design Work," Proceedings of the 6th Asian Design International Conference, Tsukuba.

Flurscheim, C. H. (1983). Industrial Design in Engineering. London, The Design Council.

Fraser, I. and R. Henmi (1994). "Envisioning Architecture-An Analysis of Drawing," New York: Van Nostrand Reinhold. Quoted in: Do, Ellen Yi-Luen (2002) "Drawing marks, acts, and reacts: Toward a computational sketching interface for architectural design," Artificial Intelligence for Engineering Design, Analysis and Manufacturing No.16 pp. 149-171.

Frishberg, N. (2006). "Prototyping with Junk." Interactions(January February).

Garner, S. (2004). T211 Design and Designing - An Introduction to Design \& Designing. Milton Keynes, The Open University.

Gershenson, J. and L. Stauffer (1999). "Taxonomy for design requirements from corporate customers". Research in Engineering Design No. 11, pp. 1035. Quoted in: Ostergaard K. and Summers, J. (2009) "Development of a Systematic Classification and Taxonomy of Collaborative Design Activities" Journal of Engineering Design Vol. 20 No. 1.

Goldschmidt, G. (1992). "Serial sketching: Visual problem solving in designing," Cybernetics and Systems Vol. 23 pp 191-219. Quoted In: Verstijnen, I. M.; Hennessey, J. M. ;Van Leeuwen, C.; Hamel, R.; Goldschmidt, G. (1998) "Sketching and creative discovery," Design Studies Vol. 19 No. 4.

Goldschmidt, G. (1997). "Capturing indeterminism: representation in the design problem space." Design Studies Vol. 18(No. 4).

Goldschmidt, G. (2007). "To see eye to eye: the role of visual representations in building shared mental models in design teams." CoDesign Vol. 3(No. 1): pp. $43-50$.

Goldschmidt, G. and W. L. Porter (2004). Design Representation. London, Springer-Verlag.

Haller, L. and C. D. Cullen (2006). Design Secrets Products 2 : 50 real-life projects uncovered. Gloucester, Mass., Rockport Publishers.

Herbert, D. M. (1993). Architectural Study Drawings. New York, Van Nostrand Reinhold.

Holbrook, M. B. and W. L. Moore (1981). "Feature interactions in consumer judgements of verbal versus pictorial presentations," Journal of Consumer Research No. 8 pp. 103-113. Quoted in: Söderman, Mikael (2002) "Comparing Desktop Virtual Reality with handmade sketches and real products: Exploring key aspects for end-users' understanding of proposed products," Journal of Design Research Vol. 2 No. 1. 
Holmquist, L. E. (2005). "Prototyping: Generating ideas or cargo cult designs?" Interactions Vol. 12(No. 2): pp. 48-54.

Houde, S. and Hill, C. (1997) What do Prototypes Prototype? Handbook of Human-Computer Interaction (2nd Ed.), M. Helander, T.Ê Landauer, and P. Prabhu (eds.): Elsevier Science B. V: Amsterdam.

IDSA, (2003). Design Secrets: Products: 50 Real-Life Projects Uncovered. Gloucester, Mass., Rockport Hove RotoVision.

Jeffrey, C. (1982). "An introduction to plant taxonomy", New York: Cambridge University Press. Quoted in: Ostergaard K. and Summers, J. (2009) "Development of a Systematic Classification and Taxonomy of Collaborative Design Activities" Journal of Engineering Design Vol. 20 No. 1.

Johansson, P., Persson, S., Schachinger, P. (2001). "The Use of Product Representations in Industry - A Survey Dealing with Product Development in Sweden," Proceedings of SKFC'01, The 3rd International Workshop on Strategic Knowledge and Concept Formation held in Sydney, Australia. Quoted in: Persson, Sara (2002) "Industrial Design - Engineering Design Interaction - Studies of Influencing Factors in Swedish Product Developing Industry," Thesis for the degree of Licentiate of Engineering, Chalmers University of Technology, Göteborg, Sweden.

Kalay, Y. E. (2002). "Enhancing multi-disciplinary collaboration through semantically rich representation." Automation in Construction(No. 10).

Kelly, T. (2001). "Prototyping is the Shorthand of Innovation." Design Management Journal Vol. 12(No. 3).

Kleinsmann, M. and A. Dong (2007). Investigating the Affective Force on Creating Shared Understanding. ASME 2007 International Design Engineering Technical Conferences \& Computers and Information in Engineering Conference IDETC/CIE 2007, Las Vegas, Nevada, USA 4-7 September 2007.

Kolodner, J. L. and L. M. Wills (1996). "Powers of observation in creative design," Design Studies Vol. 17 No. 4 pp. 385-416. Quoted in: Yang, Maria C. and Daniel, J. (2005) "A study of prototypes, design activity, and design outcome," Design Studies Vol. 26 No. 6.

Kurvinen, E., Koskinen, L., Battarbee, K. (2008). "Prototyping Social Interaction." Design Issues Vol. 24(No. 3).

Larkin, J. H. and H. A. Simon (1987). "Why a Diagram is (sometimes) Worth Ten Thousand Words." Cognitive Science Journal(No. 11): pp. 65-99.

Ling, B. (2006). Tips on how to improve your drawing ability: <http://www.designsojourn.com/2006/12/08/tips-on-how-to-improve-yourdrawing-ability/> Accessed on 14 December 2006. 
Lipson, H. and M. Shpitalni (2000). "Conceptual design and analysis by sketching." Artificial Intelligence for Engineering Design, Analysis and Manufacturing(No. 14): pp. 391-401.

Luzadder, W. J. (1975). "Innovative Design," London: Prentice-Hall. In: Evans, Mark Andrew (2002) "The Integration of Rapid Prototyping within Industrial Design Practice (Staff Thesis)," Loughborough: Department of Design and Technology Loughborough University.

Mathew, B. S. J. (1997). "Are traditional management tools sufficient for diverse teams?" Team Performance Management Vol. 3(No. 1): pp. 3-11.

Menezes, A. and B. Lawson (2006). "How Designers Perceive Sketches." Design Studies Vol. 27(No. 5).

Merriam-Webster Dictionary (1994). The Merriam-Webster Dictionary,. F. C. Mish (Ed.). Massachusetts, USA, Merriam-Webster.

Olofsson, E. and K. Sjölén (2005). Design Sketching. Sundsvall, Sweden, Keeos Design Books AB.

Ostergaard, K. J. and J. D. Summers (2009). "'Development of a Systematic Classification and Taxonomy of Collaborative Design Activities"." Journal of Engineering Design Vol. 20(No. 1).

Ostwald, J. (1995). Supporting Collaborative Design with Representations for Mutual Understanding. Conference on the Companion on Human Factors in Computing Systems - Mosiac of Creativity CHI '95 May 7-11, 1995, ACM Press.

Otto, K. and K. Wood (2001). Product Design - Techniques in Reverse Engineering and New Product Development. New Jersey, Prentice Hall.

Oxford Dictionary (2008) Concise Oxford English Dictionary $11^{\text {th }}$ revised edition, Oxford University Press, USA

Palmer, D. (2006). "Combining Product Design with Engineering is Key." Eureka - Innovative Engineering, Design \& Applications Vol. 18(No. 1).

Pavel, N. (2005). The Industrial Designer's Guide to Sketching. Trondheim, Tapir Academic Press.

Peng, C. (1994). "Exploring communication in collaborative design: Cooperative architectural modelling." Design Studies Vol. 15(No. 1).

Persson, S. (2002). Industrial Design and Engineering Design Interaction: Studies of Influencing Factors in Swedish Product Developing Industry: Licentiate Thesis. Department of Product and Production Development,. Göteborg, Chalmers University of Technology. 
Persson, S. and A. Warell (2003). Relational Modes between Industrial Design and Engineering Design - a Conceptual Model for Interdisciplinary Design Work. Proceedings of the 6th Asian Design International Conference (ADC'03) held in Tsukuba, Tsukuba.

Pipes, A. (2007). Drawing for Designers. London, Laurence King Publishing. Powell, D. (1990). Presentation Techniques. London, Macdonald.

Preece, J., Rogers, Y., Sharp, H. (2002). Interaction Design. New York, John Wiley \& Sons.

Robbins, E. (1994). "Why Architects Draw," Cambridge, MA: MIT Press. Quoted in: Do, Ellen Yi-Luen (2002) "Drawing marks, acts, and reacts: Toward a computational sketching interface for architectural design," Artificial Intelligence for Engineering Design, Analysis and Manufacturing No.16 pp. 149-171.

Rodriguez, W. (1992). The Modelling of Design Ideas - Graphics and Visualization Techniques for Engineers. Singapore, McGraw-Hill Book Company.

Saddler, H. J. (2001). "Understanding Design Representations." Interactions July - August.

Schenk, P. (2007) Developing a Taxonomy on Drawing for Design. International Association of Societies of Design Research, held in Hong Kong Polytechnic University, 12 - 15 November 2007.

Scrivener, S. A. R., Ball, L. J., Andre, W. (2000). Collaborative Design Proceedings of CoDesigning 2000. London, Springer-Verlag.

Smyth, M. (1998). "The tools designers use: what do they reveal about design thinking?" Idater 98 Loughborough University.

Song, S. and A. S. Agogino (2004). "Insights on designers' sketching activities in product design teams," In: ASME Design Engineering Technical Conference '04 held in Salt Lake City, Utah. Quoted in: Yang, Maria C. and Daniel, J. (2005) "A study of prototypes, design activity, and design outcome," Design Studies Vol. 26 No. 6.

Sorenson, P. F., and Webb, J. M. "An experimental evaluation of icon quality." Short talk presented at the $\mathrm{CHI}$ '91 Conference, New Orleans, LA, April 28 1991. Quoted in Lohse, G. L., Biolsi, K., Walker, N., Rueter, H. (1994) "A Classification of Visual Representations." Communications of the ACM," Vol. 37 No 12

Stacey, M. and C. Eckert (2003). "Against Ambiguity." Computer Supported Cooperative Work(No. 12): pp. 153-183. 
Suwa, M., Purcell, T., Gero, J. (1998). "Macroscopic analysis of design processes based on a scheme for coding designer's cognitive actions." Design Studies Vol. 19(No. 4): pp. 455-483.

Tang, J. C. (1991). "Findings from observational studies of collaborative work," International Journal of Man-Machine Studies Vol. 34 pp. 143-160. Quoted in: Scrivener, Stephen A. R.; Ball, Linden J. and Woodcock, Andre (2000) "Collaborative Design - Proceedings of CoDesigning 2000," London: Springer-Verlag pp. 339.

Te Duits, T. (2003). The Origins of Things - Sketches, Models, Prototypes. Rotterdam, Museum Boijmans Van Beuningen Rotterdam / NAi Publishers.

Tjalve, E., Andreasen, M. M., Schmidt, F. F. (1979). Engineering Graphic Modelling - A Workbook for Design Engineers. London, Butterworth \& Co.

Tovey, M. (1989). "Drawing and CAD in industrial design." Design Studies Vol. 10(No. 1): pp. 24-39.

Ullman, D. G. (2003). The Mechanical Design Process (3rd ed.). New York, McGraw-Hill.

Ullman, D. G., Dletterlch, T. G., Stauffer, L. A. (1988). "A model of the mechanical design process based on empirical data," Artificial Intelligence for Engineering, Design, Analysis and Manufacturing Vol. 2 No. 1 pp. 33-52. Quoted in: Culverhouse, P. F., Ball, L. and Burton, C. J. (1992) "A tool for tracking engineering design in action," Design Studies Vol. 13 No. 1.

Ullman, D. G., S., Stephen, W., David, C. (1990). "The Importance of Drawing in the Mechanical Design Process." Computer \& Graphics Vol. 14(No. 2).

Ulrich, K. T. and S. D. Eppinger (2003). Product Design and Development (3rd ed.). New York, McGraw-Hill.

Van der Lugt, R. (2005). "How sketching can affect the idea generation process in design group meetings." Design Studies Vol. 26(No. 2).

Veveris, M. (1994). The importance of the use of physical engineering models in design. IDATER 1994 Conference, Loughborough University (Design and Technology).

Visser, W. (2006). The cognitive artifacts of designing. Mahwah, Lawrence Erlbaum Associates,.

Woodtke, M. V. (2000). "Design with Digital Tools," Blacklick: McGraw Hill pp. 108. In: Evans, Mark Andrew (2002) "The Integration of Rapid Prototyping within Industrial Design Practice (Staff Thesis)," Loughborough: Department of Design and Technology Loughborough University.

Yang, M. C. (2003). "Concept generation and sketching: Correlations with design outcome," In: ASME Design Engineering Technical Conferences '03 
held in Chicago, IL. Quoted in: Yang, Maria C. and Daniel, J. (2005) "A study of prototypes, design activity, and design outcome," Design Studies Vol. 26 No. 6.

Yang, M. C. and J. G. Cham (2007). "An Analysis of Sketching Skill and Its Role in Early Stage Engineering Design." Transactions of the ASME(No. 129).

Yang, M. C. and J. Daniel (2005). "A study of prototypes, design activity, and design outcome." Design Studies Vol. 26(No. 6). 